\title{
Review Article \\ Plants-Derived Neuroprotective Agents: Cutting the Cycle of Cell Death through Multiple Mechanisms
}

\author{
Taiwo Olayemi Elufioye, ${ }^{1}$ Tomayo Ireti Berida, ${ }^{1}$ and Solomon Habtemariam ${ }^{2}$ \\ ${ }^{1}$ Department of Pharmacognosy, Faculty of Pharmacy, University of Ibadan, Ibadan, Nigeria \\ ${ }^{2}$ Pharmacognosy Research Laboratories and Herbal Analysis Services, University of Greenwich, Chatham-Maritime, \\ Kent ME4 4TB, UK \\ Correspondence should be addressed to Solomon Habtemariam; s.habtemariam@herbalanalysis.co.uk
}

Received 9 June 2017; Revised 14 July 2017; Accepted 18 July 2017; Published 22 August 2017

Academic Editor: Olumayokun A. Olajide

\begin{abstract}
Copyright (C) 2017 Taiwo Olayemi Elufioye et al. This is an open access article distributed under the Creative Commons Attribution License, which permits unrestricted use, distribution, and reproduction in any medium, provided the original work is properly cited.
\end{abstract}

\begin{abstract}
Neuroprotection is the preservation of the structure and function of neurons from insults arising from cellular injuries induced by a variety of agents or neurodegenerative diseases (NDs). The various NDs including Alzheimer's, Parkinson's, and Huntington's diseases as well as amyotropic lateral sclerosis affect millions of people around the world with the main risk factor being advancing age. Each of these diseases affects specific neurons and/or regions in the brain and involves characteristic pathological and molecular features. Hence, several in vitro and in vivo study models specific to each disease have been employed to study NDs with the aim of understanding their underlying mechanisms and identifying new therapeutic strategies. Of the most prevalent drug development efforts employed in the past few decades, mechanisms implicated in the accumulation of protein-based deposits, oxidative stress, neuroinflammation, and certain neurotransmitter deficits such as acetylcholine and dopamine have been scrutinized in great detail. In this review, we presented classical examples of plant-derived neuroprotective agents by highlighting their structural class and specific mechanisms of action. Many of these natural products that have shown therapeutic efficacies appear to be working through the above-mentioned key multiple mechanisms of action.
\end{abstract}

\section{Introduction}

Neuroprotection is a term used to refer to strategies and relative mechanisms that shield the central nervous system (CNS) from neuronal injuries caused by chronic (e.g., Alzheimer's and Parkinson's diseases) or acute (e.g., stroke) neurodegenerative diseases (NDs) [1]. These acute or chronic diseases result from breakdown and deterioration of neurons of the CNS and often result in the deterioration of the cognitive as well as the intellectual faculties of the sufferers. The onset of NDs symptoms is usually gradual as well as progressive and includes loss of memory, primarily shortterm, difficulty in learning, motor coordination, and many other functional loses $[2,3]$. Ageing, defined as a complex physiological process involving both morphological and biochemical changes that progressively unfold as we get older [1], has been found to be closely associated with NDs. Ageing stands out as a major risk factor among the other etiological factors of NDs, including hypertension, genetic and/or environmental factors, and infections. With increasing age, aggregation of proteins, inflammation, oxidative stress, and loss of neurotransmitters, which are common to the pathology of NDs, also occur more often $[1,4,5]$.

Nature remains to be a veritable source of medicines to mankind. Many important drugs such as vincristine, artemisinin, and gentamicin, which are still in use today, are obtained from natural sources or are designed on structural fingerprints of naturally occurring molecules $[6,7]$. Furthermore, traditional medicine remains a vital alternative source of medicine all over the world today with some estimate suggesting to account to about $80 \%$ of the primary health care system in some developing countries (e.g., Nigeria, Ghana, China, and India $[8,9])$. The increasing incidence of resistance (especially to antibiotics and antimalarials), undesirable side effects, high cost, and lack of efficacy after prolonged usage of the existing drugs in use has led to a 
renewed interest in the development of new drug candidates from natural sources $[10,11]$. For example, drugs such as amantadine, memantine, donepezil, selegiline, galantamine, and rivastigmine that are clinically available for the management of NDs are only able to provide symptomatic relief and slow the progression of the diseases $[12,13]$. These drugs, such as the synthetic donepezil, are also associated with side effects [14]. Hence, a great deal of research focus has been given in recent years to herbs and other natural products used in ethnomedicine around the world for age-related CNS diseases.

Numerous natural products, but primarily plants extracts, have been reported to be used in traditional medicine for neuroprotective, memory enhancing, and antiageing purposes. Examples of such plants include Ginkgo biloba, Panax ginseng, Curcuma longa, Bacopa monnieri, and Salvia officinalis $[1,15]$. These plants have been studied to confirm the traditional claim with special attention given in understanding the mechanism by which they elicit the neuroprotective effects. This review is designed to give a brief description of a number of neurodegenerative diseases, the most important pathological events associated with the diseases, and an overview of therapeutic options with some popular plantderived neuroprotective agents.

\section{Overview of Neurodegenerative Diseases}

Neurodegenerative disease is a term used to refer to various conditions which occur as a result of neuronal cell death, particularly, those of the CNS [16]. This deterioration is often associated with gradual onset of progressive symptoms, a major symptom being loss of memory. The NDs include Alzheimer's disease (AD), Parkinson's disease (PD), Lewy body dementia, multiple sclerosis, amyotrophic lateral sclerosis (ALS), and spongiform encephalopathy [13]. Of these NDs, $\mathrm{AD}$ is the most prevalent, accounting for over $60-70 \%$ of all forms of dementia [17]. Protein aggregation, inflammation, excitotoxicity, oxidative stress, and neurotoxicity have been implicated in the pathophysiology of NDs [3].

2.1. Alzheimer's Disease. The $\mathrm{AD}$ is the most prevalent and devastating disorder of the NDs. It is an incurable disease of cognition and behavioral impairment that affects social and occupational activities and is also a leading cause of institutionalization in the elderly $[1,18]$. Clinically, $\mathrm{AD}$ is characterized by a progressive and irreversible memory deficits, cognitive deterioration, and personality changes, with a mean duration of about 8.5 years between onset of clinical symptoms and death [17]. Memory impairments are first to appear in the early stage of the disease, after which motor and sensory functions are affected as the disease progresses. The onset of $\mathrm{AD}$ is usually above 65 years of age, with risk from this age doubling every 5 years. Hence, it has been suggested that the risk for $\mathrm{AD}$ for persons living into their eighties rises to $20-40 \%$ depending on a variety of factors such as population dynamics and geography [19]. As the world population continues to age in parallel with economic development, the number of people with NDs and the associated dementia also continues to increase [20]. This increase has in turn prompted an enormous increment in research interest and efforts on the discovery of new therapeutic agents for primary, auxiliary, or tertiary prevention of these diseases [21].

The pathological hallmark of $\mathrm{AD}$ is the accumulation of protein aggregates to form two major lesions, namely, neurofibrillary tangles (NFTs) and senile plaques. Senile plaques are composed of fibrillar amyloid $\beta(\mathrm{A} \beta)$ peptides produced by cleavage of the $\mathrm{A} \beta$ precursor protein (APP), whereas NFTs consist of hyperphosphorylated microtubuleassociated tau protein [22]. The mechanisms by which $\mathrm{A} \beta$ peptide aggregates act to cause AD are thought to include induction of oxidative damage [23] as well as inflammation [24] and neurotoxicity [19]. It is now known that the dysfunction of the central cholinergic system which plays a key role in the retrieval and storage of memory in the CNS is responsible for the cognitive deficit associated with AD [25-27]. Reports of substantial neocortical deficits in choline acetyltransferase (ChAT), the enzyme responsible for the synthesis of acetylcholine (ACh), discoveries of reduced choline uptake, ACh release, and loss of cholinergic perikarya from the nucleus basalis of Meynert, along with the emerging roles of ACh in learning and memory, led to the "cholinergic hypothesis of AD" [17].

2.2. Parkinson's Disease. The PD is the second most common ageing-related neurodegenerative diseases that can greatly impair quality of life with significant consequences in terms of cost of patient care [28]. Primarily a movement disorder, as opposed to AD which is mainly a cognitive disease, $\mathrm{PD}$ affects approximately $1 \%$ of the human population over the age of 60 [4]. Its classical signs include resting tremors, bradykinesia, extrapyramidal rigidity, and loss of postural reflexes such as disturbance in walking or equilibrium. The PD involves loss of dopaminergic neurons of the pars compacta region of the substantia nigra and their terminals in the corpus striatum [29]. Since neurodegeneration is not restricted to the basal ganglia, PD is also linked with nonmotor disorder like dementia. The association between PD and oxidative damage of neuronal cells has been well established. For example, the breakdown of dopamine (DA) by autooxidation has been shown to be linked to semiquinone metabolism and the generation of superoxide anion, hydrogen peroxide $\left(\mathrm{H}_{2} \mathrm{O}_{2}\right)$, and monoamine oxidase (MAO) expression [19].

2.3. Other Neurodegenerative Diseases. Amyotrophic lateral sclerosis is thought to be caused by the mutation of the gene coding for the enzyme superoxide dismutase (SOD) and also by the misfolding of the same enzyme. The ALS is incurable and has generally a median survival of three years from onset to death. Its symptoms include tripping or stumbling when running, foot and wrist drop, slurred speech, and depression $[30,31]$. Huntington disease (HD) is another incurable ND. It has an adult onset with autosomal dominant inherited disorder characterized by progressive brain degeneration, causing rapid deterioration and eventually death. Symptoms 
of the diseases include involuntary movement, dementia, and behavioral changes [32].

Prion diseases refer to a group of rare NDs caused by the aggregation of misfolded prion proteins. Prion proteins are known to be infectious and are presumed to cause some type of NDs referred to as spongiform encephalopathy: for example, Creutzfeldt-Jacob disease and kuru in humans, Scrapie in sheep, and bovine spongiform encephalopathy in pigs collectively referred to as prion diseases. A major feature of these diseases is that they are transmissible $[33,34]$.

Cerebrovascular diseases such as stroke cause acute degeneration of the CNS unlike the previously discussed chronic NDs. About $85 \%$ of stroke cases are of ischemic origin and have a slightly different etiology from the chronic ND. Interruption of blood supplies to the brain leads to a cascade of events that causes irreversible neuronal damage. Stroke is said to be the second leading cause of death in industrialized countries [35] and has been reported to lead to dementia in $25 \%$ of patients within three months after a stroke [36]. Interestingly, the deposition of both $A \beta$ and APP in the cortical and subcortical brain areas of nondementia patients following stroke has been reported [37].

\section{Ageing}

Ageing has been defined as a complex physiological process involving both morphological and biochemical changes that occur progressively [1]. These changes include those of the CNS, the skin, the cardiovascular system, and hormonal and reproductive systems. Ageing remains to be the leading risk factor for NDs except for the familial forms which are found to affect individuals younger than $60[1,4,5]$. Human life expectancy has increased rapidly over the past decades especially in developed countries, and as the world populations get older, age-related NDs such as $\mathrm{AD}$ and $\mathrm{PD}$ have become more common $[4,38]$.

Although neuronal cell death is not programmed to occur at a particular age, cellular and molecular changes that occur with ageing interact with genes and environmental factors to determine which cells age successfully and which will suffer neurodegeneration [5]. Ageing is associated with mitochondrial dysfunction, increased free radical production and oxidative stress, microglia dysfunction, reduced efficiency of chaperones, reduced synaptic densities, bloodbrain barrier disruption, and low levels of neurogenesis [5, 39, 40]. The accumulation of deletions of mitochondrial DNA in ageing alongside functional impairment of neurons results in age-related genetic changes in the substantia nigra [41]. The oxidative neuronal damage in the ageing brain is also associated with the decline in the production and function of antioxidant enzymes [41]. Oxidative damage to the mitochondrial DNA is believed to be caused by free radicals of mitochondrial origin. Furthermore, ageing comes with an alteration in the composition of the cell membrane fatty acids. The polyunsaturated fatty acids (PUFAs), like arachidonic acids, are abundant in ageing brain and are highly susceptible to oxidative damage like lipid peroxidation. Histopathological changes also occur with microglia morphology and activity during neuroinflammation in the aged brain. Moreover, aged microglia have shorter and less motile processes and larger soma sizes compared with microglia in younger animals [42]. Also, phagocytosis function of the microglia appears to be altered in the aged brain [43], and aged microglia exhibit increased expression of the phagosomal/lysosomal associated marker. There is increased levels of proinflammatory cytokines such as interleukin-6 (IL-6), IL-1 $\beta$, and tumour necrosis factor (TNF), as well as altered levels of the anti-inflammatory cytokines such as IL10 and transforming growth factor (TGF) $\beta 1$ [39].

Progressive accumulation of iron in the brain and substantia nigra with age renders neuronal cells more susceptible to toxins [44]. The sirtuins, members of the histone deacetylase family of proteins, are also vital for cellular functions and play a role in ageing. Inhibition of sirtuin 2 (SIRT2) has been shown to rescue the toxicity of $\alpha$-synuclein and modified inclusion morphology in animal models of PD, indicating a link between ageing and neurodegeneration [45]. The activity of proteasome, whose function is linked to the degradation of damaged or ubiquitinated proteins, is also known to be reduced with ageing. Consequently, an increase in abnormal deposition of cellular brain proteins continues with the ageing process [46]. The insulin/insulin-like growth factor 1 (IGF1) signaling pathway that serves as a lifespan, metabolism, and stress-resistance regulator has been found to be associated with neurodegeneration during the ageing process. As the optimal functioning of this pathway is key to maximizing longevity, a reduction of insulin signaling results in diabetes, reduced longevity, and prevalent protein aggregation-mediated toxicity [47]. There is also increasing evidence to suggest that cognitive dysfunction due to loss or decline of the cholinergic activity in the key areas of the brain is a normal biological process associated with ageing as well as some forms of progressive neurodegenerative disorders such as $\mathrm{AD}[48]$.

\section{Common Pathophysiological Hallmark of Neuronal Cell Death}

4.1. Protein Misfolding and Aggregation. For proteins to properly function in the biological system, they must maintain their three-dimensional conformation. The process by which polypeptide chains fold into this three-dimensional structure is termed protein folding. The correct three-dimensional structure, which is dependent on the sequence of amino acids, is very essential in the proper functioning of the protein. This intricate stepwise process can however go wrong leading to the adoption of abnormal configuration by the protein, a process called protein misfolding. Misfolded proteins lose their natural activity and in several cases become deleterious and are unable to return to their native conformation. These proteins expose hydrophobic terminals that are supposed to be buried in their core leading to the formation of insoluble aggregates. Since misfolded conformation can be generated spontaneously at low rate throughout life, their aggregates gradually accumulate as we age. These aggregates form distinct and observable structures 
in the brain which are generally known as amyloid deposits in the brain. Furthermore, some form of mutation increases the chance of misfolding in proteins which is the case in the genetic or familial case of NDs [22].

Though the mechanism is not clear, it has been proven that deposits of misfolded proteins are known to be neurotoxic and able to cause apoptosis in neuronal cells. There are however mechanisms that are able to inhibit aggregation of proteins and protect the CNS from such danger. Examples of these include the chaperones that are able to bind to misfolded protein and cause them to fold into their native structure and also the "ubiquitination" reaction. However, when these systems are unable to cope, aggregation takes place and the subsequent neuronal cell death becomes inevitable $[46,49]$.

As described in the preceding texts, two microscopic features resulting from the misfolding of proteins are observed in AD: extracellular amyloid plaques (senile plaque) consisting of amorphous extracellular deposits of $A \beta$ and the NFTs of the hyperphosphorylated microtubule-associated tau protein $[1,22]$. Amyloid deposits consist of aggregates containing 40 or 42 amino acid residues. Aggregates of 42 residue are more likely to form and are also overproduced when there is a genetic mutation [22]. In rare cases of early onset of PD which runs in some families, mutations in a synaptic protein called $\alpha$-synuclein that was originally identified from smaller peptides isolated in amyloid-containing fractions of AD brains are observed [50, 51]. The $\alpha$-synuclein proteins are synaptic proteins that are able to aggregate and form fibrils and are the major component of the Lewy body lesions, characteristic of PD as well as certain cases of $\mathrm{AD}$ and several other neurodegenerative conditions [52]. In the HD, mutation of huntingtin, a cytoplasmic protein, leads to its aggregation and forms inclusions in cell nucleus in the brain. These aggregations, alongside the interaction of mutated huntingtin protein with regulatory caspases, are believed to be component of the pathophysiology of HD [53]. In the case of ALS, it is the SOD that aggregates. There is evidence to suggest that the accumulation of SOD aggregate may lead to inflammation and neurotoxicity [54].

4.2. Oxidative Stress. Oxidative stress occurs when the body's antioxidant defense system can no longer cope with the neutralization of free radicals and/or reactive oxygen species (ROS) produced in the body. Free radicals have incomplete electron shells making them more chemically reactive than molecules with complete electron shells. They are formed in the course of normal cellular respiration and metabolism, especially under the influence of certain environmental chemicals and sunlight. When an oxygen molecule $\left(\mathrm{O}_{2}\right)$ becomes electrically charged, it tries to steal electrons from neighboring molecules, causing damage to the DNA and other molecules. This damage may over time become irreversible, thereby leading to damage of cells and the body. The ROS are highly reactive molecules produced in the course of oxygen metabolism in the mitochondrial respiratory chain [55-59]. The term ROS when used implies superoxide radicals $\left(\mathrm{O}_{2}{ }^{--}\right)$, hydroxyl radicals $\left({ }^{\circ} \mathrm{OH}\right)$, hydrogen peroxide $\left(\mathrm{H}_{2} \mathrm{O}_{2}\right)$, and hydroperoxyl radicals $\left({ }^{\circ} \mathrm{HO}_{2}\right)$. Other ROS include reactive sulphur species and the reactive nitrogen species such as nitric oxide (NO) and peroxynitrite $\left(\mathrm{O}=\mathrm{N}-\mathrm{O}-\mathrm{O}^{-}\right)$. The brain with only $2 \%$ of the body mass but responsible for about $20 \%$ of the oxygen utilization is particularly susceptible to oxidative damage $[1,59]$. Furthermore, the brain tissues are readily susceptible to lipid peroxidation reactions due to the high amount of PUFAs present in neuronal membranes. The result of this is the formation of cytotoxic aldehydes, such as malondialdehyde (MDA) and 4-hydroxynonenal [55-60]. Several studies have shown that cellular damage arising from free radicals and/or ROS is implicated in the etiology and pathophysiology of NDs and several other diseases [55-61].

4.3. Inflammation. Inflammation is part of the complex physiological response of the body to harmful stimuli or body injury by internal or external mechanical, chemical, or immunological agents. This protective mechanism can however become deleterious when it became excessive or out of control. In NDs, inflammation may result from aggregation of misfolded proteins, accumulation of abnormally modified cellular components, response to molecules released following neuronal injuries, and faulty regulation of inflammatory control mechanisms [62]. In $\mathrm{AD}$, microglia are closely associated with neurons expressing $\mathrm{A} \beta$. On the other hand, $\mathrm{A} \beta$ deposits in the brain are thought to be associated with an inflammatory response leading to increased levels of proinflammatory cytokines, complement components, and acute phase proteins [63]. Microglial cells act through a conserved group of receptors called pattern recognition receptors (PRRs). These PRRs include Toll-like receptors (TLRs) which bind conserved molecular motifs displayed by pathogenassociated molecular patterns (PAMPs) expressed by infectious agents or endogenous danger-associated molecular patterns (DAMPs) released from damaged tissues. Among DAMPs that have been identified are A $\beta, \alpha$-synuclein, and microtubule-associated protein tau. Microglia and astrocytes can express various TLRs that once bound to their ligands, can stimulate the production of proinflammatory cytokines like TNF- $\alpha$ and IL- 6 and chemokine such as IL-8 $[64,65]$.

As in $\mathrm{AD}$, increased levels of proinflammatory cytokines are common in the blood, cerebrospinal fluid, and postmortem brain tissue of PD [66, 67]. Microglia induce the release of inflammatory cytokines and lead to activation of inflammation-mediating enzymes like matrix metalloproteinases (MMPs) following activation by $\alpha$-synuclein [68, 69]. A component of inflammasomes, nucleotide-binding domain, and leucine-rich repeat family, pyrin domain containing 3 (NLRP3), is expressed by activated microglia. Inflammasomes stimulate several inflammatory processes including the maturation of IL- $1 \beta$ which has been reported to worsen $\mathrm{AD}$ and PD progression in animal models [70]. Nonsteroidal anti-inflammatory drugs have hence been proposed to have protective effects [71].

The neuroprotective role of microglia, cytokine, and other inflammation and immune mechanisms of the CNS are 
also well known [72]. For instance, microglia in the CNS has a role of clearing apoptotic cells and debris. There is also an evidence to show that microglia participates in the elimination of fibrillar $\mathrm{A} \beta$ through macropinocytosis [73]. However, chronic activation of microglia may lead to loss of this protective property causing an enhanced production of various cytokines which impair phagocytosis and other processes necessary for cell survival [74]. The new concept of "neuroinflammation" attempts to explain the involvement of inflammation in the pathology of $\mathrm{AD}$ and other NDs using available studies. However, the controversy as to whether inflammation is beneficial or detrimental to the CNS of ND patients is yet to be resolved. Consequently, "a common perspective, which implies that, under pathological conditions, inflammation may exert both detrimental and protective functions depending on local factors and the timing of immune activation and shutting-off systems" was proposed [72].

4.4. Neurotransmitter Level. A number of neurotransmitters and associated biochemical processes are involved in the pathology of NDs. These include ACh, DA, and MAO. Low level of neurotransmitters such as ACh and DA characterized the two major neurodegenerative diseases, $\mathrm{AD}$ and $\mathrm{PD}$, respectively. A loss or downregulation of the neuronal nicotinic acetylcholine receptors (nAChRs) as well as loss of the central cholinergic neurons is associated with the pathogenesis of the AD brain [73].

The MAO catalyzes oxidative deamination of monoamines leading to the production of $\mathrm{H}_{2} \mathrm{O}_{2}$, aldehyde, ammonia, and amine, all of which have been found to be toxic at high concentrations and contribute to the pathology of NDs [74]. Accordingly, MAO-B inhibitors have been reported to provide mild symptomatic effects and to reduce the incidence of motor fluctuations in PD with fewer side effects. They also modify the disease state thus making them ideal candidates for the early treatment of the disease [75].

The DA is a neurotransmitter synthesized by mesencephalic neurons of the substantia nigra and ventral tegmental area and by hypothalamic neurons of the arcuate and periventricular nuclei [76]. Proper control of the DA levels and DA receptor interaction is important for normal functioning of the brain and several neurological and psychiatric disorders results from dysfunctional dopaminergic system. The dopaminergic pathways are implicated in several neurological and psychiatric diseases: for example, reduced levels of DA in PD, degeneration of selected DA neurons in $\mathrm{HD}$, and dysfunctions of the dopaminergic system in ischemia and epilepsy [77]. Dopamine has also been shown to have either neuroprotective or neurotoxic effects in different physiological and pathological conditions $[76,78,79]$.

\section{Overview of the Current Pharmacotherapy}

There is no cure for NDs and all current therapeutic interventions are aimed at managing the symptoms and improvement in the quality of life in patients. Therapies for AD, PD, and other NDs provide symptomatic improvement by several mechanisms such as restoring the levels of neurotransmitters or controlling the metabolism of neurotransmitters involved in the diseases $[1,12,13,21]$. With the abounding evidences that the central cholinergic system plays a key role in the retrieval and storage of memory items in the CNS of mammals [25-27], some current therapeutic strategies are aimed at boosting the endogenous level of ACh in order to enhance the cholinergic deficits [80]. Some of these strategies include the use of muscarinic $\mathrm{M}_{2}$ autoreceptor inhibitors [81] and nicotinic agonists [82]; ACh releasers or donors [83]; ACh precursors [84]; and acetylcholinesterase (AChE) inhibitors which act by inhibiting the hydrolysis of ACh in the synaptic cleft thereby restoring the levels of the neurotransmitter [85, 86]. Among these strategies, enhancing cholinergic deficit using agents that can inhibit $\mathrm{AChE}$ has been the main focus of attention by researchers in recent years [27].

Most of the currently available US FDA-approved drugs for the treatment of cognitive impairment such as donepezil, tacrine, galanthamine, and rivastigmine elicit their memory enhancing effects mainly by inhibiting AChE $[12,87]$. In 2003, memantine was approved for the management of moderate to severe cases of $\mathrm{AD}$. It is a low affinity and noncompetitive $\mathrm{N}$-methyl-D-aspartate (NMDA) receptor antagonist able to counteract neurotoxicity due to excitotoxicity of glutamate, the major excitatory neurotransmitter in the brain [1], without interfering with the physiological actions of glutamate necessary for memory and learning $[12,88]$. Medications for PD include levodopa, a precursor of DA; DA receptor agonist like bromocriptine and ropinirole which can act on the dopamine receptors in the CNS; and anticholinergic drugs such as benztropine which acts to give symptomatic relief to tremors and muscle stiffness [89]. Also, drugs are given to take care of nonmotor symptoms of the disease. Examples include nortriptyline for depression related symptoms and the AChE inhibitors such as donepezil and rivastigmine [90].

\section{Classical Examples of Neuroprotective Drugs of Plant-Origin and Their Mechanisms of Action(s)}

6.1. Polyphenols. Polyphenols are diverse groups of plant secondary metabolites present in fruits, vegetables, legumes, cereals, and beverages like tea, coffee, and wine. One of the most common classes of polyphenols are the C6-C1 structural group of hydroxybenzoic acid derivatives such as protocatechuic (1) and gallic acid (2) that are derived from the shikimic acid biosynthesis pathway (Figure 1). The other diverse group of shikimic acid products of phenolics are the C6-C3 metabolites (phenylpropanoids) such as cinnamic (3), $p$-hydroxy cinnamic (4), and caffeic (5) and ferulic (6) acids which are abundant in many vegetables, fruits, and seeds (e.g., coffee beans).

The other major classes of natural polyphenolic compounds are flavonoids that constitute the C6-C3-C6 structural configurations (Figure 1). Structurally, they are composed of two six-member aromatic rings designated as Aand B-rings, joined together by three-carbon chain that may cyclise to form the third ring-C (7, Figure 1). Biosynthetically, 
<smiles>[R]c1cc(C(=O)O)cc(O)c1O</smiles>

$1 \mathrm{R}=\mathrm{H}$ protocatechuic acid $2 \mathrm{R}=\mathrm{OH}$ gallic acid

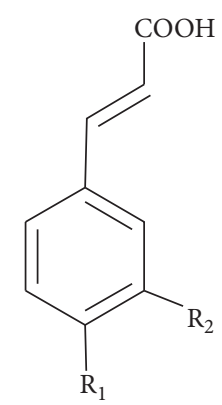

$3 \mathrm{R}_{1}=\mathrm{R}_{2}=\mathrm{H}$ cinnamic acid

$4 \mathrm{R}_{1}=\mathrm{OH}, \mathrm{R}_{2}=\mathrm{H}$, p-hydroxy cinnamic acid

$5 \mathrm{R}_{1}=\mathrm{R}_{2}=\mathrm{OH}$ caffeic acid

$6 \mathrm{R}_{1}=\mathrm{OH}, \mathrm{R}_{2}=\mathrm{OMe}$ ferulic acid

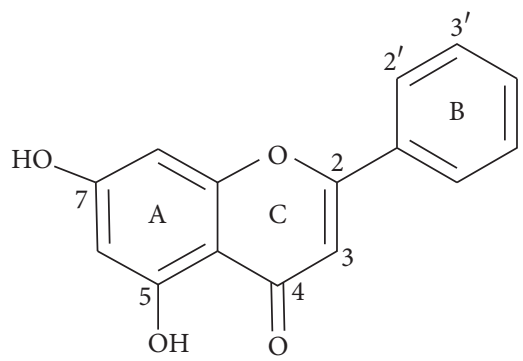

7 The flavonoid skeleton

FIGURE 1: Common phenolic compounds. Structures of aromatic acids and the flavonoid skeleton are shown.

the B-ring and linking three-carbon chain (C6-C3) are the phenylpropanoid skeleton that is derived from the shikimic acid pathway, while the other C-6 (A-ring) is an acetate pathway origin that bears the three hydroxyl groups spaced at meta positions from each other within the benzene ring. Depending on the position of attachment of the B-ring on the 3-carbon linking chain (at C-2 of the common flavonoids, C-3 of the isoflavonoids, and C-4 of the neoflavonoids), or the chemistry of the linking chain (e.g., presence/absence of a double bond, cyclisation, presence/absence of a ketone functional group), flavonoids are further divided into several classes such as flavones (apigenin, luteolin), flavonols (e.g., kaempferol and quercetin), flavanones, isoflavones, anthocyanidins, and chalcones. These polyphenolic compounds can be further esterified with each other or sugars to form polymeric macromolecules such as tannins. Although phenolic compounds are mainly derived from the shikimic acid and acetate pathways, other biosynthetic routes such as the terpenoids and alkaloids can also go through extensive aromatization and oxidation reactions to give rise to polyphenolic compounds.

One of the most important structural features of polyphenols is their potential to treat a diverse range of disease conditions including NDs and metabolic disorders (e.g., diabetes). It is also worth noting that complex diseases such as the NDs do not have one single pharmacological target and drugs working through a simple therapeutic principle (one drug $\rightarrow$ one-target $\rightarrow$ one disease) may not be effective, while drugs like polyphenols working through polypharmacology (multidrug $\rightarrow$ multitarget $\rightarrow$ multidisease/complex disease) or multifunctional (one drug $\rightarrow$ multitarget $\rightarrow$ multidisease/complex disease) principles have a far better chance to treat these diseases [91]. It is not surprising then that even reversing the neurotransmitter deficit in $A D$ and PD does not offer a cure to NDs. Our decades of research have shown that polyphenolic compounds directly scavenge ROS and offer antioxidant effects that are of benefit to various disease conditions including NDs. The phenolic structural moiety plays vital role for antioxidant effect with the catecholic functional group being optimized for such activity and the gallic acid moiety even far better in inducing general antioxidant effects [92-103]. While the catechol structural moiety can also chelate metal ions, flavonoids especially those with the C-4 keto functional group possess another site of metal chelation with the $5-\mathrm{OH}$ group, while those (e.g., flavonols) that bear a free hydroxyl group at C-3 position have even more pronounced metal chelation capability through the C-4 keto and C5/C-3 hydroxyl sites. Far beyond antioxidant effects [92-108], these polyphenols do also possess numerous other biological activities related to enzyme inhibition, gene expression, and signal transductions that attribute to numerous pharmacological effects including anti-inflammatory effects that play a significant role in NDs. Good examples of these polyphenols as well as nonphenolic compounds that have been shown to display neuroprotective effects are highlighted in the following sections.

6.1.1. Phenolic Acids, Alcohols and Their Derivatives. Acteoside (8) and echinacoside (9) are glycosides (Figure 2) obtained from the dried juicy stem of Cistanche deserticola or C. tubulosa (Orobanchaceae) as well as many other plants. They have been shown to have neuroprotective effects on dopaminergic neurons of substantia nigra in a chronically intoxicated MPTP (1-methyl-4-phenyl-1,2,3,6tetrahydropyridine) mice model of PD [109]. Acteoside (8) showed neuroprotective effects against the rotenoneinduced damage to SH-SY5Y cells [110] and attenuated the lipopolysaccharide- (LPS-) induced release of NO in RAW 264.7 cells through inhibition of NF- $\kappa$ B and activator protein-1 (AP-1) [111]. Its neuroprotective effects in the MPTP models of PD revealed that it improved behavioral deficits in C57BL/6 mice and increased the dopaminergic neurons and content of DA [112]. The neuroprotective assessment of echinacoside (9) showed that it prevents the 6-hydroxydopamine- (6-OHDA-) induced extracellular loss of monoamine neurotransmitters, such as 3,4dihydroxyphenylacetic acid (DOPAC) and homovanillic acid in rat striatum [113]. In the MPTP-intoxicated mice model, 9 reduced behavioral deficits, cell death, and MPP+-induced activation of caspase- 3 and caspase- 8 in cerebellar granule 


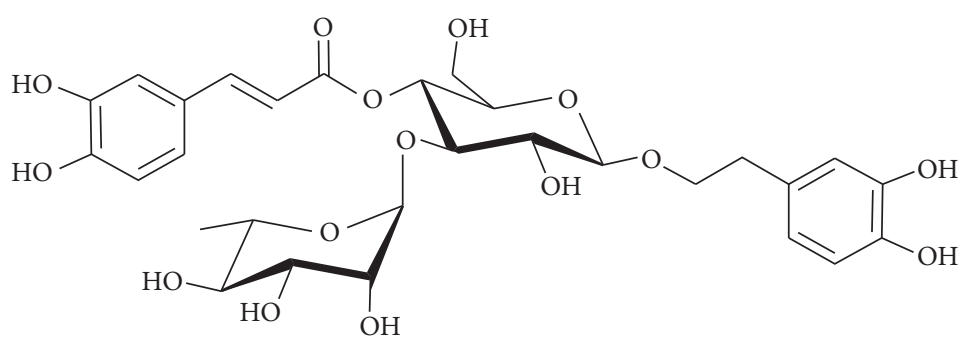

8 Acteoside

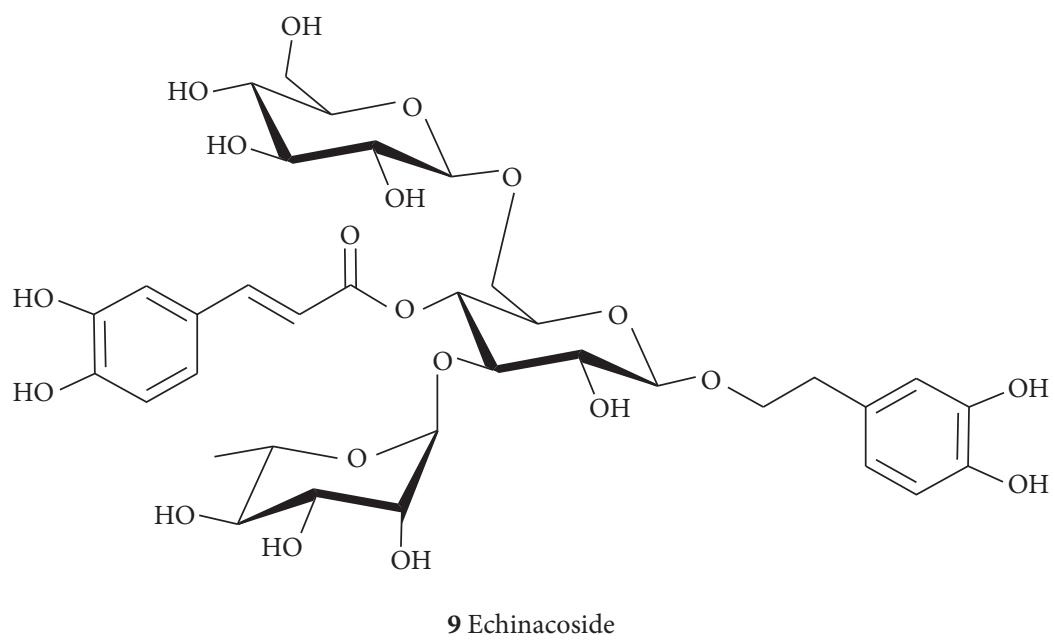

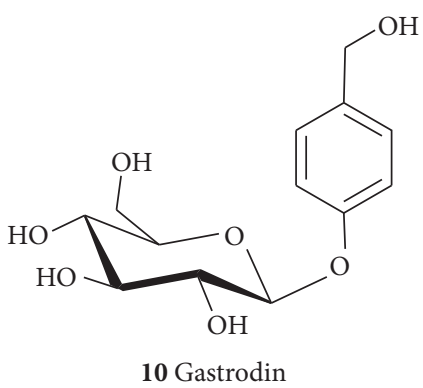<smiles>COc1cc(/C=C/C(=O)O[C@@H]2C[C@](O)(C(=O)O)C[C@H](O)[C@H]2O)ccc1O</smiles>

11 Chlorogenic acid

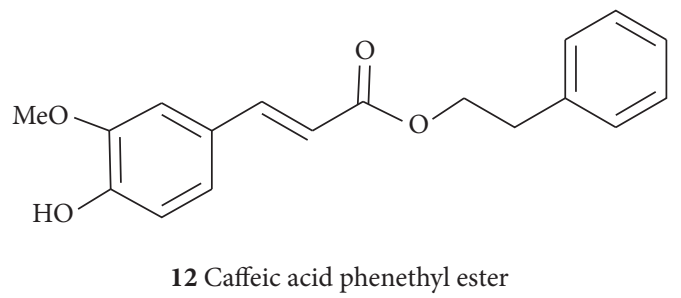

FIGURE 2: Structures of some common neuroprotective phenolic acid esters and glycosides.

neurons as well as increased tyrosine hydroxylase (TH) expression and the level of striatal DA and its metabolite [114]. The compound (9) is active orally as an inhibitor of apoptosis and inducer of neurotrophic factors [115]. There is no doubt that the active principles of these compounds $(8,9)$ are the catechol functional moiety presented in the 3,4-dihydroxyphenyl ethanol and caffeic acid moieties in their structures. The extended double bond in the caffeic acid further stabilized the free radical generation/and or scavenging making it more active as antioxidant and related pharmacological effects. The neuroprotective effect of caffeic acid as a free acid and in its ester form such as chlorogenic acid (11) and caffeic acid phenethyl ester (12) has recently been reviewed [108]. Besides the common global antioxidant effects through direct scavenging of ROS and metal chelation, caffeic acid and its derivatives display specific antiinflammatory mechanisms in the brain along with inhibition of key APP processing enzyme, $\beta$-secretase (BACE-1) [116]. Treatment of neuronal cells in vitro with 11 has been shown to reverse the $\mathrm{A} \beta$-induced neurotoxicity [117] while 12 enhances the expression antioxidant proteins such as HO-1 (heme oxygenase 1) and the Nrf2 (nuclear factor (erythroid-derived 2)-like 2) in microglia cells both in vitro and in vivo [118]. We have also shown that gallic acid (2) and related natural products display neuroprotective effects both in vitro and in vivo under a number of stress conditions [119-122]. In addition to the above-mentioned plethora of pharmacological effects, modulation of the human microRNA-17-3p expression has been shown as the possible mechanism of action for the in vitro neuroprotective effect of gallic acid derivatives [123]. Hence, compounds bearing the catechol functional groups such as gallate or caffeic acid have been proposed to offer benefit in AD and related NDs [108].

Gastrodin (10) is another example of simple derivatives of the C6-C1 shikimic acid biosynthetic products that may offer benefit in NDs. It has been obtained from Gastrodia elata (Orchidaceae) among other plants [124]. Gastrodin (10) showed neuroprotective effects in the subchronic MPTP mouse PD model by ameliorating bradykinesia and motor impairment [125]. It also protected dopaminergic neurons against neurotoxicity through regulating free radicals, Bax/Bcl-2 mRNA, and caspase-3 and cleaved poly-ADPribose polymerase (PARP) in SH-SY5Y cells stressed with $\mathrm{MPP}+[125]$. The compound also prevents neuronal apoptosis by attenuating oxidative stress and inhibits the levels of neurotoxic proinflammatory mediators and cytokines including iNOS, COX-2, TNF- $\alpha$, and IL-1 $\beta$ [126].

6.1.2. Curcuminoids and Resveratrol. The rhizomes of turmeric (Curcuma longa L., Zingiberaceae) and related species have long been known for their use as spices and medicinal properties with their characteristic yellow 
<smiles>COc1cc(/C=C/C(=O)CC(=O)/C=C/c2ccc(O)c(OC)c2)ccc1O</smiles>

13 Curcumin (diketo form)<smiles>COc1cc(/C=C/C(O)=C/C(=O)/C=C/c2ccc(O)cc2)ccc1O</smiles>

15 Demethoxycurcumin<smiles>COc1cc(CCC(=O)CC(=O)CCc2ccc(O)c(OC)c2)ccc1O</smiles>

17 Tetrahydrocurcumin<smiles>COc1cc(/C=C/C(=O)/C=C(O)/C=C/c2ccc(O)c(OC)c2)ccc1O</smiles>

14 Curcumin (keto-enol form)<smiles>O=C(/C=C(O)/C=C/c1ccc(O)cc1)/C=C/c1ccc(O)cc1</smiles>

16 Bisdemethoxycurcumin<smiles>Oc1ccc(/C=C/c2cc(O)cc(O)c2)cc1</smiles>

18 Resveratrol

FIGURE 3: Structures of curcuminoids and resveratrol.

colour attributed to the principal pharmacologically active principle, curcumin (13, Figure 3). Curcumin can exist as a diketo (13) or keto-enol form (14) while other structurally related derivatives isolated from the turmeric in significant amount include demethoxycurcumin (15) and bisdemethoxycurcumin (16). The two aromatic phenol rings which are connected by two sets of $\alpha, \beta$-unsaturated carbonyl groups are good Michael acceptor and interact with a range of biologically reactive species including glutathione and other nucleophiles, while the aryl methoxyl groups at the ortho position to the hydroxyl moiety as well as the conjugated $\beta$-diketone moieties of curcumin are important structural features for the various pharmacological activities of these compounds [127]. The range of biological activities for these compounds collectively, called the curcuminoids, has been reviewed in the various literature (e.g., [128]) and numerous synthetic analogues have also been evaluated in recent years. The presentation herein is thus limited to highlight that curcumin is one classical example of natural products that may be employed as a neuroprotective agent through multifunctional mechanism of actions.

Curcuminoids as well as the crude extracts of $C$. longa have been extensively studied for their neuroprotective effects [129-131]. They prevented MPTP mediated loss of THpositive neurons and depletion of DA in inflammationmediated neurodegeneration of dopaminergic neurons of C57BL/6 mice in the acute MPTP model. They also mitigated cytokines, generation of $\mathrm{NO}$, and the expression of protein inflammatory markers as well as improved motor deficits produced by the MPTP [129]. Curcumin (13) has also been shown to have neuroprotective effect in a 6-OHDAinduced hemiparkinsonian mice model. It decreased the 6OHDA-induced loss of striatal $\mathrm{TH}$ fibers and nigral $\mathrm{TH}-$ immunoreactive neurons indicating that the neuroprotective effects may be due to its anti-inflammatory properties, or direct protection on nigral DA neurons [131]. Curcumin was also found to ameliorate the A53T $\alpha$-synuclein-induced SH-SY5Y cell death [132] and decrease $\alpha$-synuclein-induced intracellular ROS generation and inhibit caspase- 3 activation in the SH-SY5Y cells [133]. It also protects dopaminergic neurons from apoptosis in an MPTP mouse model of PD and ameliorated the loss of dopaminergic axons. It prevents the degeneration of nigrostriatal neurons by inhibiting the dysfunction of mitochondria through abolishing the hyperphosphorylation of c-Jun N-terminal kinase (JNK) induced by MPTP [130]. Several studies have reported that curcumin has antioxidant, anti-inflammatory, and antitumor activity. In in vitro studies, curcumin inhibited the activities of $\beta$ secretase, $\mathrm{AChE}$, as well as $\mathrm{A} \beta$ aggregation, and $\mathrm{A} \beta$-induced inflammation. Studies in animal models of $\mathrm{AD}$ also indicate a direct effect of curcumin in decreasing the amyloid pathology of $\mathrm{AD}$, and oral administration resulted in the inhibition of $\mathrm{A} \beta$ deposition, $\mathrm{A} \beta$ oligomerization, and tau phosphorylation in the brains of $\mathrm{AD}$ animal models and improvements in behavioral impairment [134-140].

In comparing curcumin and its more stable metabolite, tetrahydrocurcumin (17, Figure 3 ), it was observed that the dienone bridge present in curcumin, but not in TC, is important in reducing plaque deposition and protein oxidation in an AD's model even though $\mathbf{1 7}$ reduced neuroinflammation and soluble $\mathrm{A} \beta$, an effect that can be attributed to limiting JNK-mediated transcription [135]. An alternative mechanism of curcumin in reducing $A \beta$ aggregation or oxidative neurotoxicity is through metal chelation. It interacts with copper and iron thereby offering a net protective effect against $A \beta$ toxicity and suppressing inflammatory damage by preventing the induction of NF- $\kappa \mathrm{B}$ [141]. 
Resveratrol (18) is a natural stilbene polyphenol found in red grapes, peanuts, and tea. It is found in the skin of red grape and can be extracted by fermentation of the skin. It is also found in high concentration in the oriental plant, Polygonum cuspidatum (Polygonaceae), used to treat fevers, hyperlipidemia, atherosclerosis, and inflammation [142]. Though the full understanding of its neuroprotective mechanism is yet to be outlined, in vitro and in vivo studies have shown that $\mathbf{1 8}$ can elicit a wide range of beneficial effects on NDs. Among the several possible mechanisms by which $\mathbf{1 8}$ is thought to act, its antioxidant activity seems to be most important [143]. Given that oxidative stress is implicated in the pathologies of $\mathrm{AD}, \mathrm{PD}, \mathrm{HD}$, prion disease, cerebral ischemia, ALS, and other NDs [55-61], a great deal of emphasis has been given to study the antioxidant effect of $\mathbf{1 8}$ in the respective NDs models. Furthermore, $\mathbf{1 8}$ ameliorates the deleterious effects triggered by oxidative stress through activation of SIRT1 and vitagenes which can modulate ROS production [144]. Furthermore, it acts by activating SIRT1 and the PGCl $\alpha$ pathway. Both pathways are known to lead to improved mitochondrial function and efficiency [143]. Resveratrol also inhibits $\mathrm{A} \beta$ formation through sirtuin-dependent activation as potentiation of the activity of SIRT1 has been noted [144]. The SIRT1 can deacetylate tau protein at multiple residue in vitro exposing the lysine residue to ubiquitin ligases leading to the marking of the tau protein for proteosomal degradation [145]. Allosteric modulation of resveratrol (18) on SIRT1 activates the deacetylation of $\mathrm{p} 53$, a protein that induces indirect phosphorylation of tau which has been reported to be unregulated in the superior temporal gyrus in $\mathrm{AD}$ [146].

Similarly in PD, the antioxidant properties of resveratrol (18) are believed to play major role in its neuroprotective effect on dopaminergic neurons [147]. Resveratrol also via inducing the activation and expression of SIRT1 offers protection against pathological $\alpha$-synuclein aggregation [143]. Another possible mechanism by which $\mathbf{1 8}$ can decrease $\alpha$ synuclein protein expression in cellular model of PD is through the downregulation and partial inhibition of GSK$3 \beta$ (glycogen synthase kinase 3 beta) which has been shown to protect the dopaminergic neurons from various stressinduced injuries. Resveratrol (18) can also prevent calcium elevation caused by repeated and persistent entry of calcium into the cells as a result of intracellular calcium oscillation following monoamine induced metabolism of DA and the production of $\mathrm{H}_{2} \mathrm{O}_{2}$ in $\mathrm{PD}$ patients $[58,143]$. On the basis of all the available data so far, resveratrol (18) has been widely reported as a useful natural potential therapeutic agent in managing NDs [148-154].

6.1.3. Flavonoids. Flavonoids are one of by far the best studied groups of compounds for their neuroprotective effects and a selected few are presented here as classical examples of their representative structural class. Baicalein (19, Figure 4) belongs to the flavone class of flavonoids that has been isolated as the principal component of Scutellaria baicalensis (Labiatae). Structurally, this compound has trihydroxy substitution in the A-ring that mirrors that of the gallate (2) bioactive structural moiety. The compound has been evaluated for its neuroprotective effect in the 6-OHDAinduced cellular and animal models of parkinsonism. It promoted neurite outgrowth in PC12 cells and attenuated the 6-OHDA-induced cell apoptosis in the SH-SY5Y cells. It also attenuated muscle tremor in 6-OHDA-lesioned rats and mitigated against astroglial response and increased $\mathrm{TH}-$ positive neurons in substantia nigra [155]. The effect of baicalein (19) on rotenone-induced neurotoxicity in PC12 cells was also evaluated. It inhibits the accumulation of ROS, suppressed rotenone-induced apoptosis and production of ROS, promotes mitochondrial active respiration, and prevents the rotenone-induced deficiency of ATP and swelling of isolated brain mitochondria [156]. Baicalein (19) also protects the SH-SY5Y cells from $\alpha$-synuclein oligomerinduced toxicity [157] and against the MPTP-induced fall of TH-positive neurons in the substantia nigra as well as preventing an MPTP-induced decrease in DA levels [158]. It has also been shown to improve impaired spontaneous motor activity and rotarod performance induced by MPTP in C57BL/6 mice [158]; modulate the balance between glutamate and gamma amino butyric acid [159]; increase the counts of dopaminergic neurons [103]; and enhance the levels of DA and 5-hydroxytryptamine in the striatum [158]. Baicalein (19) also inhibits the following: cytochrome oxidase subunit I (CO-I) mRNA expression in the subthalamic nucleus [115], the oxidative stress and the astroglial response [160], the oligomerization of $\alpha$-synuclein in cell-free and cellular systems, $\alpha$-synuclein fibrillation in cell-free systems, and the formation of $\alpha$-synuclein oligomers in HeLa and $\mathrm{SH}-$ SY5Y cells [157]. On the other hand, the ethanolic extract of $S$. baicalensis was shown to decrease the LPS-induced expression of inducible nitric oxide synthase (iNOS), NO, cyclooxygenase-2 (COX-2), and prostaglandin E2 levels in BV-2 and RAW264.7 cells [160]. The neuroprotective effect of 19 through antioxidant and mitochondrial mechanisms hs also been reviewed [161].

Flavonoids have also generally been implicated in the management of AD [162-164]. Hence, baicalein (19) has been reported to prevent $A \beta$-induced impairments in hippocampal LTP through activation of Akt phosphorylation and memory deficits in $\mathrm{AD}$ model. It also inhibits 12/15lipoxygenases and GSK $3 \beta$ activity, reduces BACE1 and $A \beta$ production, prevents tau phosphorylation, and restores spine density and LTP in AD model $[165,166]$. In addition to inhibiting $\mathrm{A} \beta$-induced depolarization, 19 also functions as an antagonist of AMPA ( $\alpha$-amino-3-hydroxy-5-methyl-4isoxazolepropionic acid) and NMDA receptors and improves neurocognition $[167,168]$. It also attenuates neurological deficits and preserves blood-brain barrier integrity in a rat model of intracerebral hemorrhage and inhibits AChE [169-172]. Recently, cocrystals of baicalein with isoniazid, isonicotinamide, caffeine, and theophylline were developed with BaiCaf having superior powder dissolution and pharmacokinetic behaviors [173].

Pinocembrin (20) is a flavonoid (favanone subclass) isolated from several plants including the Pinus heartwood, Eucalyptus, Populus, Euphorbia, and Sparattosperma leucanthum [174]. The neuroprotective effects of 20 against cerebral ischemic injury have been reported with a wide therapeutic 
<smiles>O=C(O[C@H]1Cc2c(O)cc(O)cc2O[C@H](c2ccc(O)c(O)c2)C1)c1cc(O)c(O)c(O)c1</smiles>

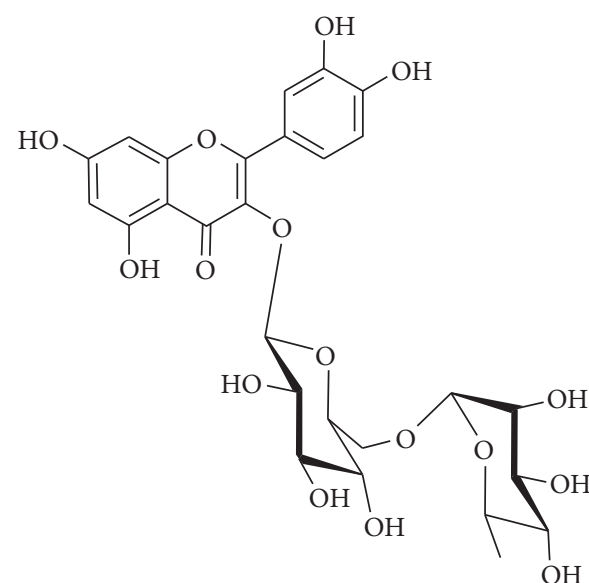

22 Rutin<smiles>O=c1c(-c2ccc(O)cc2)coc2c(C3OCC(O)C(O)C(O)C3O)c(O)ccc12</smiles>

23 Puerarin

Figure 4: Examples of flavonoids with neuroprotective effects.

window that has been shown to be attributed to its antiexcitotoxic effects [175]. It has been shown that $\mathbf{2 0}$ alleviates cerebral ischemic injury induced by occlusion of the middle cerebral artery in rats $[176,177]$ as well as enhanced cognition by protecting cerebral mitochondria structure and function against chronic cerebral hypoperfusion in rats [178]. Other mechanisms of action include increasing ADP : oxygen ratio, glutathione, state 3 respiration state, neuronal survival rates, and oxidative phosphorylation rate in $\mathrm{NADH} / \mathrm{FADH}_{2}$ and decreasing LDH release, ROS, NO, neuronal NOS (nNOS), iNOS, and 4 respiration state (V4) in NADH [177]. It also enhances ATP content in brain mitochondria in the SHSY5Y cells $[175,179]$. Furthermore, it decreased brain edema, improved cerebral blood flow, and increased the viability and mitochondrial membrane potential of cultured rat cerebral microvascular endothelial cells [180]. Pinocembrin (20) also possesses anti-inflammatory $[181,182]$ and antioxidant activities [183, 184]. Pinocembrin improves cognition and protects the neurovascular unit in Alzheimer-related deficits and inhibits $\mathrm{A} \beta$-induced neurotoxicity through $\mathrm{Nrf} 2 / \mathrm{HO}-1$ pathway in the SH-SY5Y cells [185-187].

The consumption of tea has been shown to be inversely correlated with the incidence of dementia, AD, and PD due primarily to its main catechin polyphenol constituent (-)-epigallocatechin-3-O-gallate (21) among others. The (-)epigallocatechin-3-O-gallate (21) has been reported to show neuroprotective effects in many cellular and animal models of neurological disorders. In addition to the known antioxidant activity of catechins, the modulation of signal transduction pathways, cell survival/death genes, and mitochondrial function all contribute significantly to the induction of neuron viability [188]. Recent studies have linked the biological activities of catechins to their ability to modulate various protein kinase signaling pathways in addition to their antioxidant/radical-scavenging potential [188, 189]. Hence, 21 has been shown to improve cognitive decline associated with age as well as protect against cerebral ischemia/reperfusion injuries [190] and brain inflammation and neuronal damage in experimental autoimmune encephalomyelitis [191]. It also prevented striatal DA depletion and substantia nigra dopaminergic neuron loss in the MPTP PD model [192]. It reduces cerebral amyloidosis in AD's transgenic mice [193] and prevented neuronal cell death due to 6-OHDA, 1-methyl-4-phenylpyridinium and A $\beta[194,195]$. It boosts cellular protein stability and prevents cell damage and cell death by modulating macroautophagy [196]. Other complex mechanisms of action that may explain its beneficial neuroprotective effects have also been reported [197].

The flavonol glycoside, rutin (22), its aglycone quercetin, and a related glycoside isoquercetin (quercetin 3-Oglucoside) have been shown to possess neuroprotective effects on glutamate-induced oxidative injury in the 


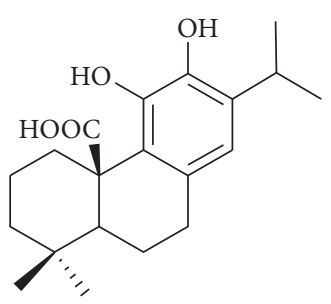

24 Carnosic acid

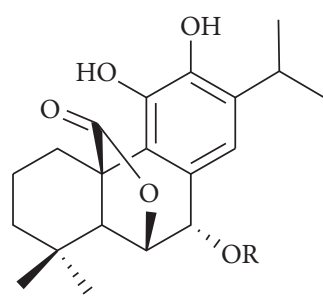

$25 \mathrm{R}=\mathrm{H}$ rosmanol $26 \mathrm{R}=\mathrm{CH}_{3}$

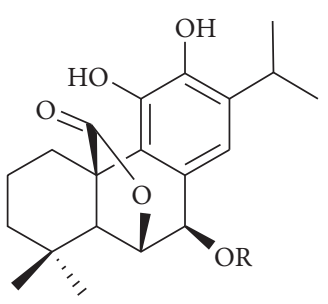

27 Epirosmanol

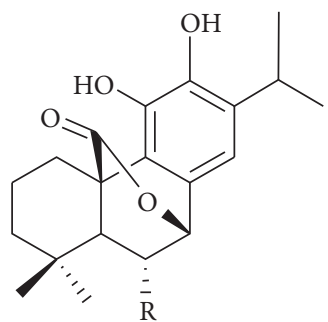

$28 \mathrm{R}=\mathrm{H}$ carnosol $29 \mathrm{R}=\mathrm{OH}$ isorosmanol

FIGURE 5: Bioactive phenolic compounds from Rosemary with potential neuroprotective effects.

HT22 hippocampal cells [198, 199]. Rutin (22) reportedly reduces the levels of ROS, MDA, NLRP3 (NLR family pyrin domain containing 3), ASC (apoptosis-associated speck-like protein containing a CARD), caspase-1, IL-1 $\beta$, and IL-18 and attenuates histologic alteration as well as improving locomotion recovery [200]. Quercetin also dose-dependently reduced the $\mathrm{A} \beta-\left(\mathrm{A} \beta_{(1-42)^{-}}\right)$induced paralysis in Caenorhabditis elegans by decreasing the amount of aggregated proteins [201] and antagonized the high glucose-induced damage of Schwann cells by inducing autophagy [202]. Rutin (22) attenuates the isoflurane-induced neuroapoptosis by modulating JNK (cJune-N-terminal kinase) and p38 MAPK (mitogen-activated protein kinase) pathways in the hippocampi of neonatal rats [203]. It also protects against neuronal damage in vitro and ameliorates doxorubicin-induced memory deficits in vivo in Wistar rats [204]. Rutin (22) has also shown to inhibit protein aggregate formation, depolymerize aggregates, and reduce neurotoxicity [205]. Details of the mechanism of action of rutin and related compounds have been outlined in our previous review communication [199].

Puerarin (23) is an example of the isoflavonoid subclass of flavonoid compounds that has been obtained from Pueraria lobata (Leguminosae) [206, 207]. It has been observed to upregulate the phosphorylation of Akt in MPP+-induced cytotoxicity in SH-SY5Y cells and inhibits MPP+-induced nuclear translocation of $\mathrm{p} 53$, expression of Bax, and caspase3-dependent programmed cell death [208]. Puerarin (22) was also reported to prevent the dysfunction of the proteasomal system thus preventing the accumulation of conjugated proteins [209]. It was shown to suppress the LPS-induced release of iNOS and phosphorylation of MAPKs in N9 cells [210] and inhibits the MPP+-induced phosphorylation of JNK [211]. In 6-OHDA-lesioned rats, 23 significantly increased the protein expression of DJ-1 and SOD-2 in the substantia nigra [212] and increased the expression of the glial cell-derived neurotrophic factor in the striatum of rats administered with 6-OHDA [213]. Other studies have also shown the neuroprotective effects of 23 in AD [214, 215]. Puerarin also suppresses the $A \beta_{(1-42)}$-induced primary cortical neuron death [216] thus protecting against $\mathrm{A} \beta_{(1-42)^{-}}$ induced learning and memory impairments in mice [217]. It also attenuates myocardial hypoxia/reoxygenation injury by inhibiting autophagy via the Akt signaling pathway and inhibits oxidative stress in STZ-induced SAD mice [218, 219]. Overall, numerous reports from our laboratories and others have shown the neuroprotective effects of various classes of flavonoids (e.g., [220, 221]). Extensive literature review articles in the field are also available [220-226].

6.1.4. Other Phenolic Compounds. Numerous phenolic compounds that are not of the acetate/shikimate pathway origin but with promising neuroprotective effects have been reported [227]. Of significance are the diterpenoids Rosmarinus officinalis (24-29, Figure 5) which have significant antioxidant, anti-inflammatory, antiamyloid, and anti-AChE activities [228]. Carnosic acid (24) from $R$. officinalis was reported to have neuroprotective effects on cyanide-induced brain damage in cultured rodent [229] while the protective effects of carnosol (28) in vitro on rotenone-induced neurotoxicity in cultured dopaminergic cells have also been reported [230]. The antioxidant potential of carnosic acid (24) and carnosol (28) has been well documented and their detailed neuroprotective mechanism have been reviewed recently [228]. For example, carnosic acid protects neuronal cells from ischemic injury by scavenging ROS [231] while carnosol inhibits the $\mathrm{CU}^{2+}$-induced LDL oxidation [232] and chelate $\mathrm{Fe}^{2+}$ [233]. On inflammation, carnosol (28) inhibits the adhesion of TNF- $\alpha$-activated monocytes to endothelial cells and suppresses the expression of intercellular adhesion molecule at the transcriptional level [234]. It also inhibits the TNF- $\alpha$-induced signaling pathways through inhibitor of $\mathrm{NF} \kappa-\mathrm{B}$ (IKK- $\beta$ ) activity as well as the upregulation of HO1 expression [235]. Both carnosic acid (24) and carnosol (28) antagonized intracellular $\mathrm{Ca}^{2+}$ mobilization induced by a chemotactic stimulus, coupled with inhibition of ROS generation [236]. Carnosic acid (24) also suppressed A $\beta 42$ secretion [237, 238] and inhibited AChE [239, 240] and its therapeutic potential for $\mathrm{AD}$ both in vitro and in vivo is well documented [241, 242].

6.2. Alkaloids. Galantamine (30, Figure 6) is an alkaloid originally isolated from Galanthus woronowii (Amaryllidaceae) and related species including G. caucasicus as well as from the related genera like Narcissus, Leucojum (Leucojum aestivum), and Lycoris (Lycoris radiate) [243]; but now it can also be obtained synthetically. With the trademark of 
<smiles>COc1ccc2c3c1O[C@@H]1C3C(=C[C@@H]1O)CN(C)C2</smiles>

30 Galanthamine<smiles>CCN(C)C(=O)Oc1cccc(C(C)N(C)C)c1</smiles>

31 Rivastigmine

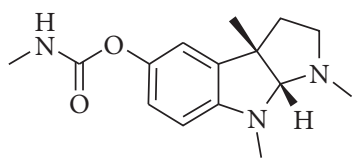

32 Physostigmine<smiles>COc1ccc2cc3[n+](cc2c1OC)CCc1cc2c(cc1-3)OCO2</smiles>

33 Berberine<smiles>O=C(O)CCc1c[nH]c2ccccc12</smiles>

34 Indole-3-propionic acid

FIGURE 6: Examples of alkaloids with neuroprotective effects.

Razadyne or Nivalin, galantamine (30) is an approved drug for the treatment of mild to moderate dementia in AD. Much work on its identification and properties was done by Mashkovsky and Kruglikova-Lvova in the 1950s. Before the FDA approval for its use for the management of $\mathrm{AD}$ in the US, the compound has been used for decades in Eastern Europe and Russia for various indications such as treatment of poliomyelitis, myasthenia, and myopathy. It had also found clinical use as anesthetics to reverse neuromuscular paralysis by tubocurarine-like muscle relaxants [244]. Galantamine (30) acts as a selective, competitive, and reversible inhibitor of AChE with very little butyrylcholinesterase (BuChE) inhibitory activity [244]. The selectivity is in the range of 10-50-fold for AChE than for BuChE [245]. As a competitive inhibitor, it competes with $\mathrm{ACh}$ at the $\mathrm{AChE}$ binding site, and since this is dependent on ACh concentration, it may be less likely to bind to the enzymatic site in areas with high ACh concentration [246]. It is also proposed to be an allosteric ligand at $\mathrm{nAChR}$ thereby inducing its modulatory effect leading to enhanced effect of $\mathrm{ACh}$ and cholinergic transmission [86]. The neuromodulatory activity at nicotinic receptors in addition to its effect on cholinergic transmission affects other neurotransmitter systems such as monoamines, glutamate, and $\gamma$-aminobutyric acid (GABA). These effects may improve cognitive dysfunction and psychiatric illness in schizophrenia, major depression, bipolar disorder, and alcohol abuse [247]. Galanthamine (30) showed protective effects on NO-mediated glutamate neurotoxicity when tested on primary cultures from the cerebral cortex of fetal rats. It also prevented the glutamate- and ionomycin-induced neurotoxicity [248]. The neuroprotective effect against both acute and moderate glutamate treatments was mediated through nAChRs $\alpha 4$ - and $\alpha 7$ and phosphatidylinositol 3kinase-Akt pathway [249, 250]. Galanthamine appears less tolerated when compared to other approved drugs but better toleration was noted when gradually titrated over more than three months [86].
Rivastigmine (trade name Exelon, 31) is another approved drug of natural origin for the treatment of $\mathrm{AD}$. It is a semisynthetic derivative of physostigmine (32) obtained from Physostigma venenosum (Fabaceae). Also called Calabar bean, $P$. venenosum was used for ordeal poisoning by locals in the 19th century [251]. Rivastigmine, a powerful carbamate inhibitor, inhibits both BuChE and AChE by covalently binding to the esteratic part of the active site of the $\mathrm{AChE}$ in a slow-reversible manner. In addition to $\mathrm{AD}$, rivastigmine is also indicated for the management of Lewy body dementia and PD dementia [252]. Rivastigmine (31) which was initially formulated in tablet form is now available as transdermal drug delivery systems (drug "patches") which has the advantage of providing controlled and continuous delivery of drugs through the skin, minimizing the processing of the drug in the liver, stomach, and intestines as well as improving compliance [85]. It is also able to reduce the side effects associated with the use of the drug [86].

Berberine (33) is an isoquinoline alkaloid of the protoberberine type isolated from numerous plants with multiple therapeutic implications. It shows neuroprotective effect in various animal models of CNS-related disorders [253, 254]. Berberine (33) has D2 dopamine receptor antagonist and D1 dopamine receptor agonist effects [255]. It reverses the $\mathrm{A} \beta_{(1-40)}$-induced memory [256], reduces $\mathrm{A} \beta$-production by modulating APP processing in human neuroglioma $\mathrm{H} 4$ cells [257], and inhibits AChE [258, 259]. It also reversed the NMDA-induced excitotoxicity [260] and reduced D1 DA and NMDA receptor bindings in the cortex [261]. Given that berberine (33) is a multifunctional compound with broad range of pharmacological effects ranging from antiinflammatory and antioxidant to neuroprotection in a variety of models [262], it has been the subject of intense medicinal chemistry researches that aim to synthesize a better novel lead derivative compound [263]. The rather simple compound, indole-3-propionic acid (34) that can be obtained by deamination of the amino acid tryptophan, is a further example 


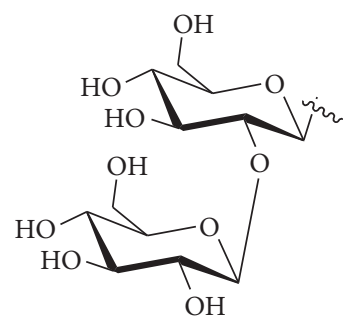

A

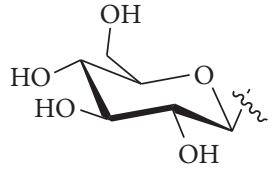

B

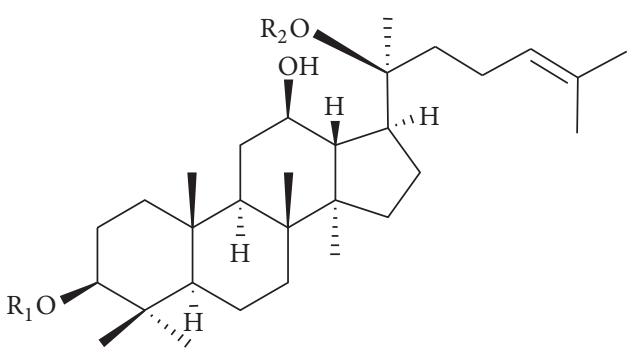

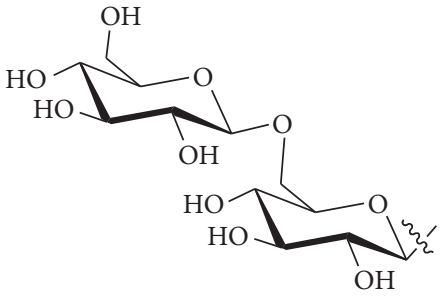

C

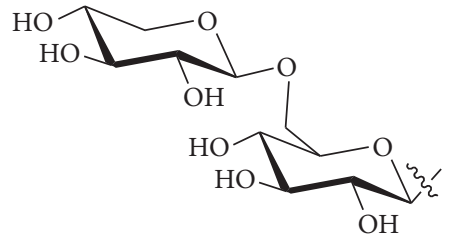

D

$\begin{array}{ll}35 \mathrm{R}_{1}=\mathrm{A}, \mathrm{R}_{2}=\mathrm{B} & \text { Ginsenoside } \mathrm{Rd} \\ 36 \mathrm{R}_{1}=\mathrm{A}, \mathrm{R}_{2}=\mathrm{C} & \text { Ginsenoside } \mathrm{Rb} 1 \\ 37 \mathrm{R}_{1}=\mathrm{A}, \mathrm{R}_{2}=\mathrm{D} & \text { Ginsenoside } \mathrm{Rb} 2 \\ 38 \mathrm{R}_{1}=\mathrm{A}, \mathrm{R}_{2}=\mathrm{H} & \text { Ginsenoside } \mathrm{Rg} 3 \\ 39 \mathrm{R}_{1}=\mathrm{H}, \mathrm{R}_{2}=\mathrm{B} & \text { Ginsenoside CK } \\ 40 \mathrm{R}_{1}=\mathrm{R}_{2}=\mathrm{H} & \text { Protopanaxadiol }\end{array}$

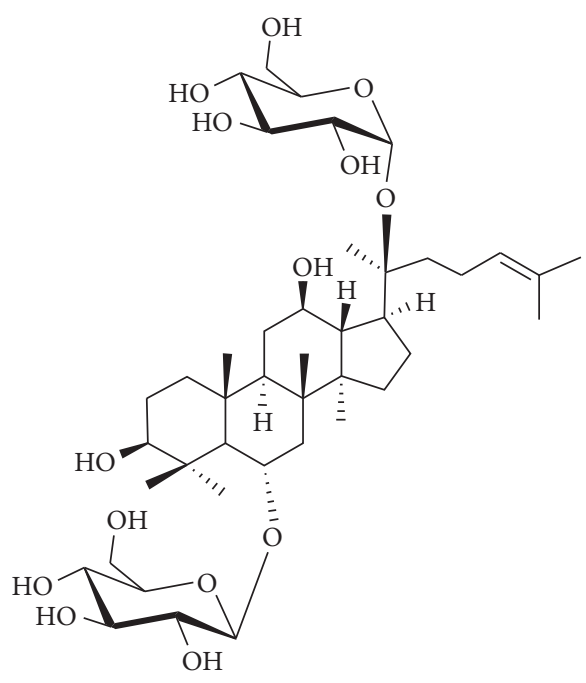

41 Ginsenoside Rg1

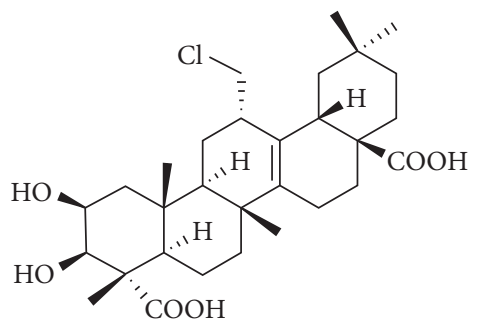

42 Tenuigenin/senegenin

FIGURE 7: Structures of ginsenosides and tenuigenin.

of neuroprotective natural products that can be obtained through a simple biosynthetic route [264]. Compound 34, isolated from Clostridium sporogenes (Gram-positive bacteria), has been reported as a potent antioxidant that attenuates neuronal damage and oxidative stress in the CNS [265]. It has also been detected in the plasma and cerebrospinal fluid of humans [266] where it offers complete protection to primary neurons and neuroblastoma cells against oxidative damage and death caused by exposure to $A \beta$ [267]. This suggests that 34 may form part of the body's natural defense against neuronal injuries due to free radicals [267] which is the basis for the development of some probiotic drugs such as $\mathrm{OXIGON}^{\mathrm{TM}}$ for the management of NDs.

\subsection{Terpenoids}

6.3.1. Triterpenoids. Ginsenosides (35-41, Figure 7) are good examples of neuroprotective triterpenoids obtained from the roots and rhizomes of $P$ ginseng and $P$. notoginseng (Araliaceae) [268]. The aqueous extract of $P$. ginseng has been evaluated for its neuroprotective effects against the MPP+induced cytotoxicity in SH-SY5Y human neuroblastoma cells [129]. It was observed that the extract reduced the overproduction of reactive ROS, release of cytochrome $c$, and activation of caspase- 3 and elevated $\mathrm{Bax} / \mathrm{Bcl}-2$ ratio, thereby increasing the cell survival. Ginsenoside $\mathrm{Rg} 1$ (41) was reported to decrease the cytotoxicity induced by $\mathrm{H}_{2} \mathrm{O}_{2}$ in PC12 cells thus explaining its antioxidant activity. It also protects cells from injury induced by $\mathrm{H}_{2} \mathrm{O}_{2}$ by downregulating the ERK1/2 (extracellular signal-regulated kinases 1/2) as well as decreasing the activation of the NF- $\kappa \mathrm{B}$ signaling pathway [269]. Other studies showed that ginsenoside Rg1 (41) renews an iron-induced reduction in mitochondrial transmembrane potential, inhibits the 6-OHDA-induced upregulation of an iron importer protein divalent metal transporter 1 with iron 
responsive element (DMT1-IRE), inhibits iron regulatory proteins, thereby downregulating the DMT1-IRE expression [270], inhibits the MPP+-induced upregulation of DMT1IRE [271], attenuates the MPTP-induced elevated iron levels, decreases the expression of DMT1, and increased ferroportin1 expression [272].

Ginsenoside Rg1 (41) was found to have a neuroprotective effect in dopaminergic neurons through IGF1 receptor signaling pathway in a 6-OHDA-induced nigrostriatal injury model of PD [273]. It also has protective effects on dopaminergic neurons in ovariectomized female SD rats injected intracerebroventricularly with 6-OHDA [274]. Compound 41 also has anti-inflammatory effect: it inhibits proinflammatory markers such as iNOS, NO, and TNF- $\alpha$ and expression of ionized calcium binding adaptor molecule 1 in both the cerebral cortex and hippocampus of mice as well as suppressing effect on the downstream inflammatory markers [275]. Saponins obtained from $P$. notoginseng also showed potent neuroprotective effect on MPP+-induced toxicity to PC12 cells and Kunming mice [276, 277].

Ginsenoside-Rg1 (41) has neuroprotective effect on cerebral ischemia/reperfusion injury in rats by downregulating protease-activated receptor-1 expression [278]. It can reduce neuronal death induced by hypoxic-ischemic insults, an effect probably mediated by the activation of glucocorticoid receptors, and by the inhibition of calcium influx through NMDA receptors and L-type voltage-dependent $\mathrm{Ca}^{2+}$ channels and the resultant reduction of intracellular free $\mathrm{Ca}^{2+}$ [279]. It also enhances neurite outgrowth and protects against neurotoxicity induced by $\mathrm{A} \beta$ through a mechanism involving Akt and ERK 1/2 signaling [280]. This compound (41) is also shown to be capable of helping Schwann cells recover from the oxidative insult induced by $\mathrm{H}_{2} \mathrm{O}_{2}$. It upregulates the level of SOD, GSH, and CAT and decreased the level of MDA in Schwann cells treated with $\mathrm{H}_{2} \mathrm{O}_{2}$ both in vitro and in vivo (sciatic crush injury model in rats). It has also shown to inhibit the proapoptotic effect of $\mathrm{H}_{2} \mathrm{O}_{2}$, as well as the detrimental effect of $\mathrm{H}_{2} \mathrm{O}_{2}$ on cell number and cell viability. Furthermore, it increases the mRNA levels, protein levels, and secretion of nerve growth factor and brain-derived neurotrophic factor in Schwann cells after incubation with $\mathrm{H}_{2} \mathrm{O}_{2}$ [281]. Ginsenoside $\mathrm{Rg1}(41)$ as well as 38 and others have been shown to reduce the amount of $\mathrm{A} \beta$ detected in the brains of animals after single oral doses [280]. Review articles on the effects of ginseng extracts and isolated ginsenosides along with the aglycones relevant to cognition in humans are also available $[282,283]$.

Tenuigenin (42) obtained from the dried root of Polygala tenuifolia (Polygalaceae) [284] is another example of a triterpenoid neuroprotective agent. Evaluation in the 6OHDA-induced cytotoxicity in SH-SY5Y cells showed that tenuigenin (42) increased cell viability and reduced cell death [284]. It also protects against the 6-OHDA-induced damage of the mitochondrial membrane and increased glutathione and SOD expression [284]. It has also been shown to downregulate the caspase- 3 activity at the translational level and upregulate the expression of TH in 6-OHDA thus indicating neuroprotective effects on dopaminergic neurons through antiapoptotic and antioxidant mechanisms [284]. It also showed neuroprotective effect on neuroinflammation induced by the LPS in adult male SD rat by significantly improving the level of DA in the striatum and preventing the LPS-induced upregulation of cytokines [285].

Tenuigenin (42) exerts an anti-inflammatory effect by downregulating the release of NO, MMP-9, and cytokines. It can decrease the release of NO from the LPS-activated rat microglia in a dose-dependent manner and directly scavenge the NO radical. It has also been shown to decrease the secretion and mRNA levels of MMP-9 and proinflammatory cytokines (TNF- $\alpha / \mathrm{IL}-1 \beta$ ) in activated microglia as well as inhibit the secretion of MMP-2 [286]. It has also been reported that tenuigenin (42) inhibits the LPS-induced TNF$\alpha$, IL- $1 \beta$, IL- 6 , and PGE $_{2}$ production while the expression of Nrf2 and HO-1 was shown to be upregulated in a dosedependent manner. In in vivo studies, it relieved the LPSinduced memory deficit in the Morris water maze and passive avoidance tests. This suggests the anti-inflammatory mechanism of neuroprotection through activation of the Nrf2-mediated HO-1 signaling pathway [287].

6.3.2. Diterpenoids. In addition to the polyphenolic diterpenoids of Rosemary that have already been discussed in the preceding sections, several other diterpenes have been shown promising effect as neuroprotective agents. Ginkgolides (43-49, Figure 8) are a group of diterpenoids isolated from Ginkgo biloba (Ginkgoaceae), an ancient Chinese tree known for its health prompting effects. There have been several reports on the neuroprotective properties of G. biloba [288-290]. Hence, the extract of G. biloba has been reported to offer neuroprotection in the MPTP-induced nigrostriatal dopaminergic toxicity in C57 mice [291]. The various ginkgolides isolated from the plant have also been linked with neuroprotection. Ginkgolides protect PC12 cells against hypoxia-induced injury by $\mathrm{p} 42 / \mathrm{p} 44$ MAPK pathwaydependent upregulation of HIF- $1 \alpha$ (hypoxia-inducible factor $1 \alpha$ ) expression and HIF-1-DNA binding activity [292]. The neuroprotective effect of ginkgolide $K$ (50), for example, on glutamate-induced cytotoxicity in PC12 cells has been demonstrated and shown to be mediated through inhibition of ROS generation and $\mathrm{Ca}^{2+}$ influx [293]. Ginkgolide K (50) has also shown to reduce the volume of infarction and brain water content and improve neurological deficit score in ischemia-reperfusion-induced cerebral injury. It also reversed the level of MDA, NO, NOS, and SOD. Neuronal injury was also significantly improved following pretreatment with ginkgolide K (50) [294]. Ginkgolide B (44) and bilobalide (51) have also shown to exert neuroprotection under normoglycemia, while ginkgolide B (44) reduces ROS species and MDA levels in both normoglycemia and hyperglycemia ischemic rats [295]. Bilobalide (51) has also been previously reported with multiple mechanisms of action for its neuroprotection effect, including preservation of mitochondrial ATP synthesis, inhibition of apoptotic damage induced by staurosporine or by serum-free medium, suppression of hypoxia-induced membrane deterioration in the brain, and actions of increasing the expression of the mitochondrial 


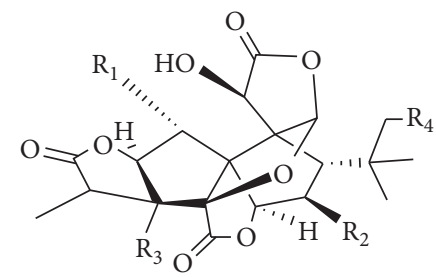

$43 \mathrm{R}_{1}=\mathrm{R}_{2}=\mathrm{R}_{4}=\mathrm{H}, \mathrm{R}_{3}=\mathrm{OH}$ ginkgolide $\mathrm{A}$ $44 \mathrm{R}_{1}=\mathrm{R}_{3}=\mathrm{OH}, \mathrm{R}_{2}=\mathrm{R}_{4}=\mathrm{H}$ ginkgolide $\mathrm{B}$ $45 \mathrm{R}_{1}=\mathrm{R}_{3}=\mathrm{OH}, \mathrm{R}_{2}=\mathrm{R}_{4}=\mathrm{H}$ ginkgolide $\mathrm{C}$ $46 \mathrm{R}_{1}=\mathrm{R}_{4}=\mathrm{H}, \mathrm{R}_{2}=\mathrm{R}_{3}=\mathrm{OH}$ ginkgolide $\mathrm{J}$ $47 \mathrm{R}_{1}=\mathrm{R}_{2}=\mathrm{OH}, \mathrm{R}_{3}=\mathrm{R}_{4}=\mathrm{H}$ ginkgolide $\mathrm{M}$ $48 \mathrm{R}_{1}=\mathrm{R}_{2}=\mathrm{H}, \mathrm{R}_{3}=\mathrm{R}_{4}=\mathrm{OH}$ ginkgolide $\mathrm{P}$ $49 \mathrm{R}_{1}=\mathrm{R}_{3}=\mathrm{R}_{4}=\mathrm{OH}, \mathrm{R}_{2}=\mathrm{H}$ ginkgolide $\mathrm{Q}$

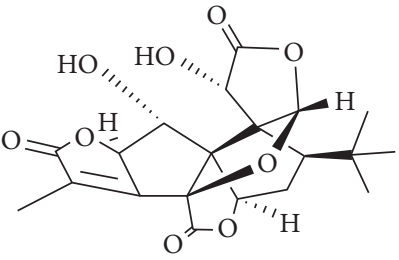

50 Ginkgolide K

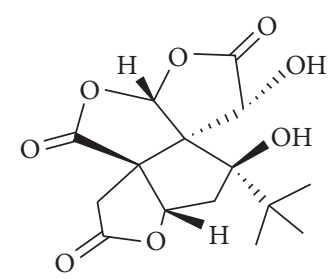

51 (-)-Bilobalide

FIGURE 8: Structures of ginkgolides and related compounds.<smiles>Cc1coc2cc(CO)c3c(c12)C[C@H](C)CC3</smiles>

52 Commiterpene A<smiles>CO[C@H]1C[C@@H](C)[C@H](OC(C)=O)c2c1c(C)cc1occ(C)c21</smiles>

53 Commiterpene B<smiles>CO[C@H]1C[C@H](C)Cc2c1c(C)cc1c2[C@@](C)(O)C(=O)O1</smiles>

54 Commiterpene $\mathrm{C}$

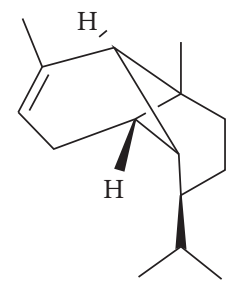

$55 \alpha$-Copaene

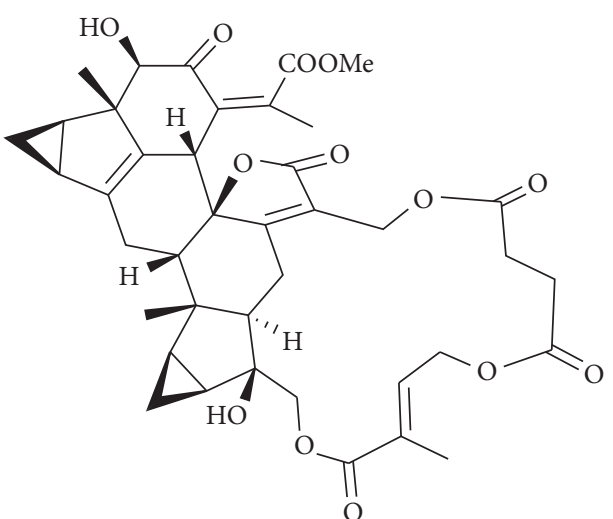

56 Shizukaol B<smiles></smiles>

57 Zederone epoxide<smiles>C=C1CCC[C@]2(C)C=C3OC(=O)C(C)=C3C[C@H]12</smiles>

58 Atractylenolide-I

FIgURE 9: Structures of selected neuroprotective sesquiterpenes.

DNA-encoded COX III subunit of cytochrome $c$ oxidase and the NADH dehydrogenase subunit 1 [296]. Ginkgolide B (44) also inhibits the 6-OHDA-induced apoptosis of PC12 by upregulating the calbindin D28K mRNA and by decreasing the intracellular calcium concentration [297] and protects against ischemic stroke [298]. Ginkgolide B (44) has also been reported to attenuate the $A \beta_{(1-42)}$-induced oxidative damage and altered cellular responses in human neuroblastoma (SH-SY5Y) cells [299].
6.3.3. Sesquiterpenes. Three cadinane sesquiterpenes, commiterpenes A-C (52-54, Figure 9) isolated from the resinous exudates of Commiphora myrrha (Burseraceae), were reported to show neuroprotective effects against the $\mathrm{MPP}^{+}$-induced neuronal cell death in SH-SY5Y cells [300]. Also, tricyclic sesquiterpene $\alpha$-copaene (55) prevents the $\mathrm{H}_{2} \mathrm{O}_{2}$-induced neurotoxicity [301]. Shizukaol B (56) is a lindenane-type dimeric sesquiterpene isolated from Chloranthus henryi (Chloranthaceae). It has anti-inflammatory 


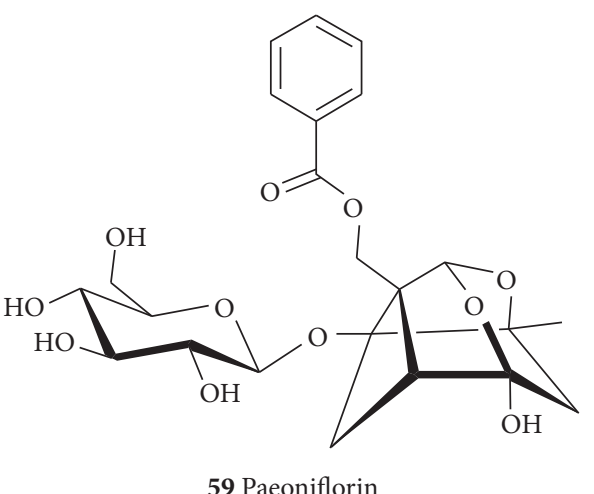

Figure 10: The structure of the monoterpenoid, paeoniflorin.

effects in the LPS-activated microglia partly by modulating JNK-AP-1 signaling pathway. Shizukaol B (56) has been shown to suppress the expression of iNOS and COX-2 and production of NO, TNF- $\alpha$, and IL-1 $\beta$ in LPS-stimulated BV2 microglia. It also inhibits the LPS-mediated JNK $1 / 2$ activation and significantly blocks the LPS-induced AP-1 activation [302]. Many other structurally related dimeric sesquiterpenes (e.g., chloramultilide A and spicachlorantin B) along with others including zederone epoxide (57) have been isolated from C. henryi with antineuroinflammatory effects. They showed significant antineuroinflammatory effects by inhibiting NO production in the LPSstimulated murine BV-2 microglial cells with relatively low cytotoxicity [303]. Atractylenolide-I (58) is isolated from the rhizomes of Atractylodes macrocephala (Asteraceae) a common medicinal plant in Chinese traditional medicine. The compound has been reported to reverse the MPTPinduced behavioral deficits, decreased microglial activation, and conferred protection to dopaminergic neurons in the mouse model of PD [304]. A number of other sesquiterpenes' neuroprotection [305] prevents $\mathrm{A} \beta_{(25-35)}$-induced toxicity in mouse cortical neurons and scopolamine-induced cognitive impairment in mice [306].

6.3.4. Monoterpenes. Paeoniflorin (59, Figure 10) obtained from Paeoniae alba Radix (Paeoniaceae) [307] has been shown to protect striatal nerve fibers and TH-positive neurons in SN; mitigate bradykinesia observed in MPTP model of PD; and ameliorate dopaminergic neurodegeneration [308]. The neuroprotective and antineuroinflammatory effects of paeoniflorin (59) can also be linked with the activation of adenosine Al receptor [308]. In the 6-OHDA-induced unilateral striatal lesion in rats, it reduced apomorphineinduced rotation [309]. It also protected PC12 cells from $\mathrm{MPP}+$ and acid-induced damage; reduced the influx of $\mathrm{Ca}^{2+}$ and its cytosolic content; upregulated microtubule-associated protein 1A/1B-light chain 3-phosphatidylethanolamine conjugate protein, and inhibited the MPP+-induced overexpression of lysosome-associated membrane protein 2a [310].

\section{General Summary and Conclusions}

A number of people living in developing countries rely on herbal medicines not only because they are considered safe but the costs associated with modern medicines are beyond the reach of many people. The growing prevalence of complex metabolic and neurodegenerative diseases in the western societies that have no drugs of cure also means that plant medicines could still be exploited as a valuable source of lead compounds as has been done throughout the history of mankind. The various biologically active secondary metabolites belonging to the polyphenols, primarily the shikimic acid and/or acetate pathways origin along with other biosynthetic pathways, and other classes of compounds including the alkaloids and terpenoids have been documented from numerous genera of plants. In this communication, these classes of compounds have been systematically presented to give an overview of plant-derived neuroprotective agents acting through diverse mechanisms of action(s). We have provided an account of some neurodegenerative diseases, some important factors in their pathogenesis, and exemplary neuroprotective drugs isolated from medicinal plants that have been used in different traditional systems of medicine.

The interlinking mechanisms of oxidative stress and inflammation in neurodegenerative diseases have been shown to play key role in processes leading to neuronal cell death. Perhaps the most important feature of the selected natural products in this communication is their multifunctional nature that seems to give the compounds significant potency through antioxidant and anti-inflammatory mechanisms among others. Associated with these mechanisms are the other linking pathological hallmarks of NDs where protein precipitation/aggregation play pivotal role in inducing the oxidative stress and unregulated inflammation that are associated with neuronal deletions in specific areas of the brain. The overall common mechanisms of action for plantderived neuroprotective agents are depicted in Figure 11. On the basis of the plethora of evidences presented for the plant-derived neuroprotective agents, further research on details of efficacy studies especially on human subjects is well warranted.

\section{Abbreviations}

6-OHDA: 6-Hydroxydopamine

$\mathrm{A} \beta: \quad$ Amyloid $\beta$

ACh: Acetylcholine

AChE: Acetylcholinesterase

AD: $\quad$ Alzheimer's disease

AKt: $\quad$ Protein kinase B

ALS: $\quad$ Amyotrophic lateral sclerosis

AMPA: $\quad \alpha$-Amino-3-hydroxy-5-methyl-4-

isoxazolepropionic acid

AMPK: AMP activated protein kinase

AP-1: Activator protein-1

APP: Amyloid precursor protein

ASC: $\quad$ Apoptosis-associated speck-like protein containing a CARD 


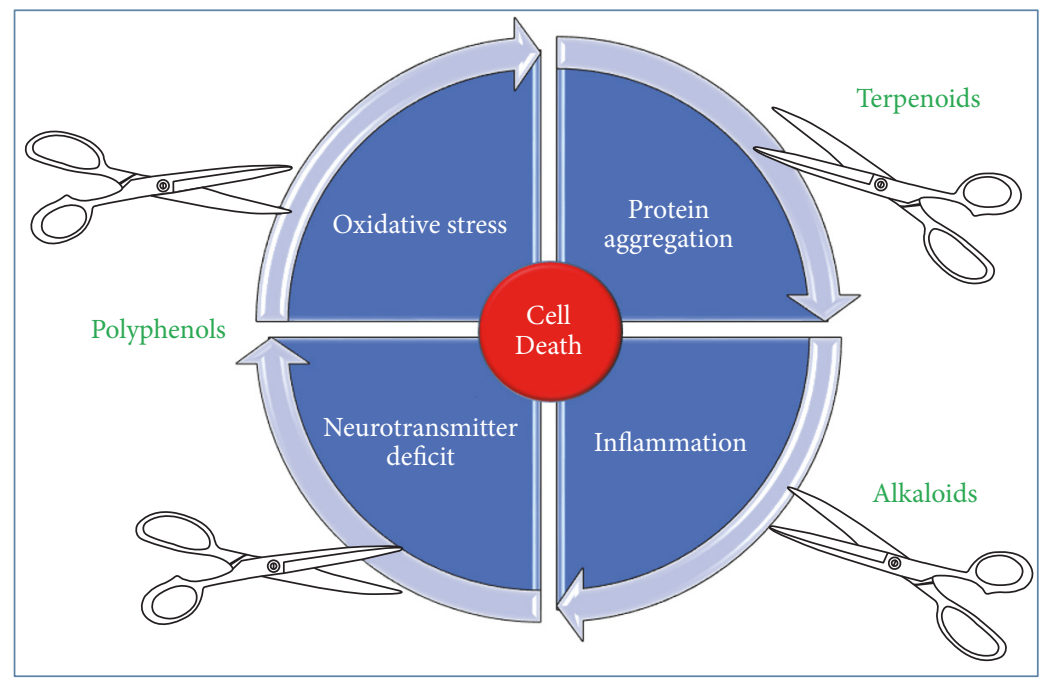

FIGURE 11: Major targets for plant-derived neuroprotective agents. Cutting the cycle of neuronal cell death through general anti-inflammatory and antioxidant mechanisms has been shown to play the key role in neuroprotection by natural products. Ameliorating the deleterious effect of protein aggregation such as $\mathrm{A} \beta$ and reversing the transmitter deficit associated with NDs through multiple mechanisms have been well documented for many plant-derived neuroprotective agents.

BACE1: Beta-secretase 1

Bax: $\quad$ BCL-2 associated X

Bcl-2: B-cell lymphoma 2

BuChE: Butyrylcholinesterase

CAT: $\quad$ Catalase

ChAT: $\quad$ Choline acetyl transferase

CNS: Central nervous system

COX2: Cyclooxygenase 2

DA: Dopamine

DAMPs: Ganger associated molecular pattern

DMT1-IRE: Divalent metal transporter 1 with iron responsive element

DMTI: Divalent metal transporter 1

ERK 1/2: $\quad$ Extracellular signal-regulated kinases 1/2

GABA: $\quad \gamma$-Aminobutyric acid

GSH: $\quad$ Glutathione, reduced form

GSK-3 $\beta$ : Glycogen synthase kinase 3 beta

$\mathrm{H}_{2} \mathrm{O}_{2}$ : Hydrogen peroxide

HD: Huntington's disease

HIF-1 $\alpha$ : Hypoxia-inducible factor $1 \alpha$

HO-1: $\quad$ Heme oxygenase 1

IGF1: Insulin-like growth factor-1

IKK- $\beta$ : $\quad$ Inhibitor of nuclear factor kappa-B kinase subunit beta

IL: Interleukin

INOS: Inducible nitric oxide synthase

IPA: Indole-3-propionic acid

IRE: Iron responsive elements

JNK: C-Jun-terminal kinase

LDH: $\quad$ Lactate dehydrogenase

LDL: Low density lipoprotein

LPS: Lipopolysaccharide

MAO: $\quad$ Monoamine oxidase

MAPK: Mitogen-activated protein kinase
MDA: Malondialdehyde

MMP: Matrix metalloproteinases

MPP+: 1-Methyl-4-phenylpyridinium

MPTP: 1-Methyl-4-phenyl-1,2,3,6tetrahydropyridine

nAChR: Nicotinic acetylcholine receptors

ND: Neurodegenerative disease

NFא-B: Nuclear factor kappa-light-chain-enhancer of activated B cells

NLRP3: NLR family pyrin domain containing 3

NMDA: $N$-Methyl-D-aspartate

NO: $\quad$ Nitric oxide

Nrf2: Nuclear factor erythroid 2-related factor 2

NTFs: Neurofibrillary tangles

-OH: Hydroxyl radical

$\mathrm{O}_{2}{ }^{\cdot-}$ : $\quad$ Superoxide radicals

PAMPs: Pathogenic associated molecular pattern

PARP: Poly-ADP-ribose polymerase

PD: $\quad$ Parkinson's disease

PRRs: Pattern recognition receptors

PUFA: Polyunsaturated fatty acid

ROS: Reactive oxygen species

SIRT: Sirtuin

SN: $\quad$ Substantia nigra

SOD: Superoxide dismutase

TGF: Transforming growth factor

TH: Tyrosine hydroxylase

TLRs: Toll-like receptors

TNF $\alpha$ : Tumour necrosis factor alpha.

\section{Conflicts of Interest}

The authors declare no conflicts of interest. 


\section{References}

[1] M. Iriti, S. Vitalini, G. Fico, and F. Faoro, "Neuroprotective herbs and foods from different traditional medicines and diets," Molecules, vol. 15, no. 5, pp. 3517-3555, 2010.

[2] E. A. Adewusi, N. Moodley, and V. Steenkamp, "Medicinal plants with cholinesterase inhibitory activity: a review," African Journal of Biotechnology, vol. 9, no. 49, pp. 8257-8276, 2010.

[3] A. Nieoullon, "Neurodegenerative diseases and neuroprotection: Current views and prospects," Journal of Applied Biomedicine, vol. 9, no. 4, pp. 173-183, 2011.

[4] A. Reeve, E. Simcox, and D. Turnbull, "Ageing and Parkinson's disease: Why is advancing age the biggest risk factor?" Ageing Research Reviews, vol. 14, no. 1, pp. 19-30, 2014.

[5] J. V. Hindle, "Ageing, neurodegeneration and Parkinson's disease," Age and Ageing, vol. 39, no. 2, pp. 156-161, 2010.

[6] S. M. K. Rates, "Plants as source of drugs," Toxicon, vol. 39, no. 5, pp. 603-613, 2001.

[7] A. L. Harvey, "Natural products in drug discovery," Drug Discovery Today, vol. 13, no. 19-20, pp. 894-901, 2008.

[8] WHO, WHO Guidelines on Safety Monitoring of Herbal Medicines in Pharmacovigilance Systems, World Health Organization, Geneva, Switzerland, 2004.

[9] M. Ekor, "The growing use of herbal medicines: Issues relating to adverse reactions and challenges in monitoring safety," Frontiers in Neurology, vol. 4, p. 177, 2014.

[10] N. H. M. A. Goldfrank, L. Lewin, and N. Flomenbaum, "The Pernicious Panacea: Herbal Medicine," Hospital Physician, vol. 18, no. 10, pp. 64-69, 1982.

[11] M. M. Cowan, "Plant products as antimicrobial agents," Clinical Microbiology Reviews, vol. 12, no. 4, pp. 564-582, 1999.

[12] L. M. Waite, “Treatment for Alzheimer's disease: has anything changed?” Australian Prescriber, vol. 38, no. 2, pp. 60-63, 2015.

[13] P. W. Chen, "The Treatment strategies for neurodegenerative fiseases by integrative medicine," Integrative Medicine International, vol. 1, pp. 223-225, 2014.

[14] R. Cacabelos, "Donepezil in Alzheimer's disease: From conventional trials to pharmacogenetics," Neuropsychiatric Disease and Treatment, vol. 3, no. 3, pp. 303-333, 2007.

[15] G. P. Kumar and F. Khanum, "Neuroprotective potential of phytochemicals," Pharmacognosy Reviews, vol. 6, no. 12, pp. 8190, 2012.

[16] P. J. Houghton and M.-J. Howes, "Natural products and derivatives affecting neurotransmission relevant to Alzheimer's and Parkinson's disease," NeuroSignals, vol. 14, no. 1-2, pp. 6-22, 2005.

[17] P. T. Francis, A. M. Palmer, M. Snape, and G. K. Wilcock, "The cholinergic hypothesis of Alzheimer's disease: a review of progress," Journal of Neurology Neurosurgery and Psychiatry, vol. 66, no. 2, pp. 137-147, 1999.

[18] N. Jivad and Z. Rabiei, "A review study on medicinal plants used in the treatment of learning and memory impairments," Asian Pacific Journal of Tropical Biomedicine, vol. 4, no. 10, pp. 780789, 2014.

[19] G. Cole, B. Teter, and S. Frautschy, "Neuroprotective effects of curcumin," Advances in Experimental Medicine and Biology, vol. 595, pp. 197-212, 2007.

[20] R. C. Brown, A. H. Lockwood, and B. R. Sonawane, "Neurodegenerative diseases: An overview of environmental risk factors," Environmental Health Perspectives, vol. 113, no. 9, pp. 1250-1256, 2005.
[21] N. Patnaik, "Cure for Alzheimer's Disease," World Journal of Neuroscience, vol. 05, no. 05, pp. 328-330, 2015.

[22] D. J. Selkoe, "Alzheimer's Disease: Genes, proteins, and therapy," Physiological Reviews, vol. 81, no. 2, pp. 741-766, 2001.

[23] M. Garcia-Alloza, S. A. Dodwell, L. A. Borrelli, S. Raju, and B. J. Bacskai, "In vivo reduction of plaque size in APPswe/PS1D9 mice treated with curcumin (P4-342)," Alzheimer's \& Dementia, vol. 2, no. 3, p. S617, 2006.

[24] R. E. Mrak and W. S. T. Griffin, "Interleukin-1, neuroinflammation, and Alzheimer's disease," Neurobiology of Aging, vol. 22, no. 6, pp. 903-908, 2001.

[25] M. E. Hasselmo, "The role of acetylcholine in learning and memory," Current Opinion in Neurobiology, vol. 16, no. 6, pp. 710-715, 2006.

[26] E. J. Okello, S. U. Savelev, and E. K. Perry, "In vitro anti$\beta$-secretase and dual anti-cholinesterase activities of Camellia sinensis L. (tea) relevant to treatment of dementia," Phytotherapy Research, vol. 18, no. 8, pp. 624-627, 2004.

[27] V. Douchamps and C. Mathis, "A second wind for the cholinergic system in Alzheimer's therapy," Behavioural Pharmacology, vol. 28, no. 2 and 3, pp. 112-123, 2017.

[28] B. Pillon, B. Deweer, Y. Agid, and B. Dubois, "Explicit memory in Alzheimer's, Huntington's, and Parkinson's diseases," Archives of Neurology, vol. 50, no. 4, pp. 374-379, 1993.

[29] H.-C. Cheng, C. M. Ulane, and R. E. Burke, "Clinical progression in Parkinson disease and the neurobiology of axons," Annals of Neurology, vol. 67, no. 6, pp. 715-725, 2010.

[30] J. Phukan and O. Hardiman, "The management of amyotrophic lateral sclerosis," Journal of Neurology, vol. 256, no. 2, pp. 176186, 2009.

[31] L. C. Wijesekera and P. N. Leigh, "Amyotrophic lateral sclerosis," Orphanet Journal of Rare Diseases, vol. 4, no. 1, p. 3, 2009.

[32] R. A. C. Roos, "Huntington's disease: a clinical review," Orphanet Journal of Rare Diseases, vol. 5, no. 1, p. 40, 2010.

[33] J. Collinge, "Prion diseases of humans and animals: Their causes and molecular basis," Annual Review of Neuroscience, vol. 24, pp. 519-550, 2001.

[34] S. B. Prusiner, "Shattuck lecture - Neurodegenerative diseases and prions," New England Journal of Medicine, vol. 344, no. 20, pp. 1516-1526, 2001.

[35] G. A. Donnan, M. Fisher, M. Macleod, and S. M. Davis, "Stroke," The Lancet, vol. 371, no. 9624, pp. 1612-1623, 2008.

[36] T. K. Tatemichi, D. W. Desmond, Y. Stern, M. Paik, M. Sano, and E. Bagiella, "Cognitive impairment after stroke: frequency, patterns, and relationship to functional abilities," Journal of Neurology Neurosurgery and Psychiatry, vol. 57, no. 2, pp. 202207,1994

[37] K. Jendroska, W. Poewe, J. Pluess et al., "Ischemic stress induces deposition of amyloid $\beta$ immunoreactivity in human brain," Acta Neuropathologica, vol. 90, no. 5, pp. 461-466, 1995.

[38] C. Reitz, C. Brayne, and R. Mayeux, "Epidemiology of Alzheimer disease," Nature Reviews Neurology, vol. 7, no. 3, pp. 137-152, 2011.

[39] J. M. Rubio-Perez and J. M. Morillas-Ruiz, "A review: inflammatory process in Alzheimer's disease, role of cytokines," The Scientific World Journal, vol. 2012, Article ID 756357, 15 pages, 2012.

[40] L. Migliore and F. Coppedè, "Environmental-induced oxidative stress in neurodegenerative disorders and aging," Mutation Research - Genetic Toxicology and Environmental Mutagenesis, vol. 674, no. 1-2, pp. 73-84, 2009. 
[41] T. B. VanItallie, "Parkinson disease: primacy of age as a risk factor for mitochondrial dysfunction," Metabolism: Clinical and Experimental, vol. 57, no. 2, pp. S50-S55, 2008.

[42] J. K. Hefendehl, J. J. Neher, R. B. Sühs, S. Kohsaka, A. Skodras, and M. Jucker, "Homeostatic and injury-induced microglia behavior in the aging brain," Aging Cell, vol. 13, no. 1, pp. 6069, 2014.

[43] K. I. Mosher and T. Wyss-Coray, "Microglial dysfunction in brain aging and Alzheimer's disease," Biochemical Pharmacology, vol. 88, no. 4, pp. 594-604, 2014.

[44] L. Zecca, M. B. H. Youdim, P. Riederer, J. R. Connor, and R. R. Crichton, "Iron, brain ageing and neurodegenerative disorders," Nature Reviews Neuroscience, vol. 5, no. 11, pp. 863-873, 2004.

[45] T. F. Outeiro, E. Kontopoulos, S. M. Altmann et al., "Sirtuin 2 inhibitors rescue $\alpha$-synuclein-mediated toxicity in models of Parkinson's disease," Science, vol. 317, no. 5837, pp. 516-519, 2007.

[46] N. P. Dantuma and L. C. Bott, "The ubiquitin-proteasome system in neurodegenerative diseases: precipitating factor, yet part of the solution," Frontiers in Molecular Neuroscience, vol. 7, article 70, 2014.

[47] E. Cohen and A. Dillin, "The insulin paradox: aging, proteotoxicity and neurodegeneration," Nature Reviews Neuroscience, vol. 9, no. 10, pp. 759-767, 2008.

[48] E. K. Perry, L. Kilford, A. J. Lees, D. J. Burn, and R. H. Perry, "Increased Alzheimer pathology in Parkinson's disease related to antimuscarinic drugs," Annals of Neurology, vol. 54, no. 2, pp. 235-238, 2003.

[49] I. Lindberg, J. Shorter, R. L. Wiseman, F. Chiti, C. A. Dickey, and P. J. McLean, "Chaperones in neurodegeneration," Journal of Neuroscience, vol. 35, no. 41, pp. 13853-13859, 2015.

[50] J.-S. Hong, "Role of inflammation in the pathogenesis of Parkinson's disease: Models, mechanisms, and therapeutic interventions," Annals of the New York Academy of Sciences, vol. 1053, pp. 151-152, 2005.

[51] E. I. Agorogiannis, G. I. Agorogiannis, A. Papadimitriou, and G. M. Hadjigeorgiou, "Protein misfolding in neurodegenerative diseases," Neuropathology and Applied Neurobiology, vol. 30, no. 3, pp. 215-224, 2004.

[52] L. Stefanis, “ $\alpha$-synuclein in Parkinson's disease," Cold Spring Harbor Perspectives in Medicine, vol. 2, no. 2, Article ID a009399, 2012.

[53] C. L. Wellington, L. M. Ellerby, C.-A. Gutekunst et al., "Caspase cleavage of mutant Huntingtin precedes neurodegeneration in Huntington's disease," Journal of Cell Biology, vol. 22, no. 4, pp. 749-759, 2002.

[54] A. M. Blokhuis, E. J. N. Groen, M. Koppers, L. H. Van Den Berg, and R. J. Pasterkamp, "Protein aggregation in amyotrophic lateral sclerosis," Acta Neuropathologica, vol. 125, no. 6, pp. 777794, 2013.

[55] J. Li, O. Wuliji, W. Li, Z.-G. Jiang, and H. A. Ghanbari, "Oxidative stress and neurodegenerative disorders," International Journal of Molecular Sciences, vol. 14, no. 12, pp. 2443824475, 2013.

[56] G. H. Kim, J. E. Kim, S. J. Rhie, and S. Yoon, "The role of oxidative stress in neurodegenerative diseases," Experimental Neurobiology, vol. 24, no. 4, pp. 325-340, 2015.

[57] B. Uttara, A. V. Singh, P. Zamboni, and R. T. Mahajan, "Oxidative stress and neurodegenerative diseases: a review of upstream and downstream antioxidant therapeutic options," Current Neuropharmacology, vol. 7, no. 1, pp. 65-74, 2009.
[58] S. Gandhi and A. Y. Abramov, "Mechanism of oxidative stress in neurodegeneration," Oxidative Medicine and Cellular Longevity, vol. 2012, Article ID 428010, 11 pages, 2012.

[59] B. Halliwell, "Oxidative stress and neurodegeneration: where are we now?" Journal of Neurochemistry, vol. 97, no. 6, pp. 1634$1658,2006$.

[60] K. J. Smith, R. Kapoor, and P. A. Felts, "Demyelination: the role of reactive oxygen and nitrogen species," Brain Pathology, vol. 9, no. 1, pp. 69-92, 1999.

[61] S. E. Atawodi, "Antioxidant potential of African medicinal plants," Journal of Biotechnology, vol. 4, pp. 128-133, 2005.

[62] T. Wyss-Coray and L. Mucke, "Inflammation in neurodegenerative disease-a double-edged sword," Neuron, vol. 35, no. 3, pp. 419-432, 2002.

[63] H. Akiyama, S. Barger, S. Barnum, and etl, "Inflammation and Alzheimer's disease," Neurobiology of Aging, vol. 21, pp. 383-421, 2000.

[64] M. Bsibsi, R. Ravid, D. Gveric, and J. M. van Noort, "Broad expression of Toll-like receptors in the human central nervous system," Journal of Neuropathology and Experimental Neurology, vol. 61, no. 11, pp. 1013-1021, 2002.

[65] S. Amor, F. Puentes, D. Baker, and P. van der Valk, "Inflammation in neurodegenerative diseases," Immunology, vol. 129, no. 2, pp. 154-169, 2010.

[66] W. Swardfager, K. Lanctôt, L. Rothenburg, A. Wong, J. Cappell, and N. Herrmann, "A meta-analysis of cytokines in Alzheimer's disease," Biological Psychiatry, vol. 68, no. 10, pp. 930-941, 2010.

[67] K. T. Akama and L. J. Van Eldik, " $\beta$-Amyloid stimulation of inducible nitric-oxide synthase in astrocytes is interleukin- $1 \beta$ and tumor necrosis factor- $\alpha$ (TNF $\alpha$ )-dependent, and involves a $\mathrm{TNF} \alpha$ receptor-associated factor- and NF $\kappa \mathrm{B}$-inducing kinasedependent signaling mechanism," Journal of Biological Chemistry, vol. 275, no. 11, pp. 7918-7924, 2000.

[68] E.-J. Lee, M.-S. Woo, P.-G. Moon et al., " $\alpha$-synuclein activates microglia by inducing the expressions of matrix metalloproteinases and the subsequent activation of protease-activated receptor-1," Journal of Immunology, vol. 185, no. 1, pp. 615-623, 2010.

[69] C. K. Glass, K. Saijo, B. Winner, M. C. Marchetto, and F. H. Gage, "Mechanisms underlying inflammation in neurodegeneration," Cell, vol. 140, no. 6, pp. 918-934, 2010.

[70] G. Singhal, E. J. Jaehne, F. Corrigan, C. Toben, and B. T. Baune, "Inflammasomes in neuroinflammation and changes in brain function: a focused review," Frontiers in Neuroscience, vol. 8, article 315, 2014.

[71] D. L. Krause and N. Müller, "Neuroinflammation, microglia and implications for anti-inflammatory treatment in Alzheimer's disease," International Journal of Alzheimer's Disease, vol. 2010, Article ID 732806, 9 pages, 2010.

[72] G. Cappellano, M. Carecchio, T. Fleetwood et al., "Immunity and inflammation in neurodegenerative diseases," American Journal of Neurodegenerative Diseases, vol. 2, no. 2, pp. 89-107, 2013.

[73] Y. Takada, A. Yonezawa, T. Kume et al., "Nicotinic acetylcholine receptor-mediated neuroprotection by donepezil against glutamate neurotoxicity in rat cortical neurons," Journal of Pharmacology and Experimental Therapeutics, vol. 306, no. 2, pp. 772777, 2003.

[74] S. K. Al-Nuaimi, E. M. MacKenzie, and G. B. Baker, "Monoamine oxidase inhibitors and neuroprotection: a review," American Journal of Therapeutics, vol. 19, no. 6, pp. 436-448, 2012. 
[75] M. Löhle and H. Reichmann, "Controversies in neurology: why monoamine oxidase B inhibitors could be a good choice for the initial treatment of Parkinson's disease," BMC neurology, vol. 11, p. 112, 2011.

[76] Y. Bozzi and E. Borrelli, "Dopamine in neurotoxicity and neuroprotection: What do D2 receptors have to do with it?" Trends in Neurosciences, vol. 29, no. 3, pp. 167-174, 2006.

[77] R. J. Jakel and W. F. Maragos, "Neuronal cell death in Huntington's disease: A potential role for dopamine," Trends in Neurosciences, vol. 23, no. 6, pp. 239-245, 2000.

[78] S. Holmes, B. Abbassi, C. Su, M. Singh, and R. L. Cunningham, "Oxidative stress defines the neuroprotective or neurotoxic properties of androgens in immortalized female rat dopaminergic neuronal cells," Endocrinology, vol. 154, no. 11, pp. 4281-4292, 2013.

[79] J. Xu, S.-Y. Kao, F. J. S. Lee, W. Song, L.-W. Jin, and B. A. Yankner, "Dopamine-dependent neurotoxicity of $\alpha$-synuclein: a mechanism for selective neurodegeneration in Parkinson disease," Nature Medicine, vol. 8, no. 6, pp. 600-606, 2002.

[80] T. O. Elufioye, E. M. Obuotor, A. T. Sennuga, J. M. Agbedahunsi, and S. A. Adesanya, "Acetylcholinesterase and butyrylcholinesterase inhibitory activity of some selected Nigerian medicinal plants," Brazilian Journal of Pharmacognosy, vol. 20, no. 4, pp. 472-477, 2010.

[81] H. N. Doods, R. Quirion, G. Mihm et al., “Therapeutic potential of CNS-active M2 antagonists: Novel structures and pharmacology," Life Sciences, vol. 52, no. 5-6, pp. 497-503, 1993.

[82] W. Greenlee, J. Clader, T. Asberom et al., "Muscarinic agonists and antagonists in the treatment of Alzheimer's disease," Il Farmaco, vol. 56, no. 4, pp. 247-250, 2001.

[83] R. Cacabelos, C. Torrellas, I. Carrera et al., "Novel Therapeutic Strategies for Dementia," CNS \& Neurological Disorders - Drug Targets, vol. 15, no. 2, pp. 141-241, 2016.

[84] S. Gauthier, L. Gauthier, R. Bouchard, R. Quirion, and S. Sultan, "Treatment of Alzheimer's Disease: Hopes and Reality," Canadian Journal of Neurological Sciences / Journal Canadien des Sciences Neurologiques, vol. 18, no. 3, pp. 439-441, 1991.

[85] T. Müller, "Rivastigmine in the treatment of patients with Alzheimer's disease," Neuropsychiatric Disease and Treatment, vol. 3, no. 2, pp. 211-218, 2007.

[86] M. B. Čolović, D. Z. Krstić, T. D. Lazarević-Pašti, A. M. Bondžić, and V. M. Vasić, "Acetylcholinesterase inhibitors: pharmacology and toxicology," Current Neuropharmacology, vol. 11, no. 3, pp. 315-335, 2013.

[87] R. T. Bartus, "On neurodegenerative diseases, models, and treatment strategies: Lessons learned and lessons forgotten a generation following the cholinergic hypothesis," Experimental Neurology, vol. 163, no. 2, pp. 495-529, 2000.

[88] E. Lancelot and M. F. Beal, "Glutamate toxicity in chronic neurodegenerative disease," Progress in Brain Research, vol. 116, pp. 331-347, 1998.

[89] M. M. Goldenberg, "Medical management of Parkinson's disease," Pharmacology \& Therapeutics, vol. 33, p. 590, 2008.

[90] W. Poewe, S. Gauthier, D. Aarsland et al., "Diagnosis and management of Parkinson's disease dementia," International Journal of Clinical Practice, vol. 62, no. 10, pp. 1581-1587, 2008.

[91] S. Habtemariam, "Going back to the good old days: The merit of crude plant drug mixtures in the 21st century," International Journal of Complementary \& Alternative Medicine, vol. 6, no. 2, pp. 1-5, 2017.
[92] S. Habtemariam, "Investigation into the antioxidant and antidiabetic potential of moringa stenopetala: Identification of the active principles," Natural Product Communications, vol. 10, no. 3, pp. 475-478, 2015.

[93] S. Habtemariam and G. K. Varghese, "Extractability of rutin in herbal tea preparations of Moringa stenopetala leaves," Beverages, vol. 1, no. 3, pp. 169-182, 2015.

[94] S. Habtemariam and G. K. Varghese, "The antidiabetic therapeutic potential of dietary polyphenols," Current Pharmaceutical Biotechnology, vol. 15, no. 4, pp. 391-400, 2014.

[95] M. Roselli, G. Lentini, and S. Habtemariam, "Phytochemical, antioxidant and anti- $\alpha$-glucosidase activity evaluations of Bergenia cordifolia," Phytotherapy Research, vol. 26, no. 6, pp. 908-914, 2012.

[96] S. Habtemariam, "Methyl-3-O-methyl gallate and gallic acid from the leaves of Peltiphyllum peltatum: isolation and comparative antioxidant, prooxidant, and cytotoxic effects in neuronal cells," Journal of Medicinal Food, vol. 14, no. 11, pp. 1412-1418, 2011.

[97] M. Juan-Badaturuge, S. Habtemariam, and M. J. K. Thomas, "Antioxidant compounds from a South Asian beverage and medicinal plant, Cassia auriculata," Food Chemistry, vol. 125, no. 1, pp. 221-225, 2011.

[98] M. Juan-Badaturuge, S. Habtemariam, C. Jackson, and M. J. K. Thomas, "Antioxidant principles of Tanacetum vulgare $\mathrm{L}$. aerial parts," Natural Product Communications, vol. 4, no. 11, pp. 1561$1564,2009$.

[99] S. Habtemariam and E. Dagne, "Comparative antioxidant, prooxidant and cytotoxic activity of sigmoidin A and eriodictyol," Planta Medica, vol. 76, no. 6, pp. 589-594, 2010.

[100] S. Habtemariam and C. Jackson, "Antioxidant and cytoprotective activity of leaves of Peltiphyllum peltatum (Torr.) Engl.," Food Chemistry, vol. 105, no. 2, pp. 498-503, 2007.

[101] S. Habtemariam, "Flavonoids as inhibitors or enhancers of the cytotoxicity of tumor necrosis factor- $\alpha$ in L-929 tumor cells," Journal of Natural Products, vol. 60, no. 8, pp. 775-778, 1997.

[102] S. Habtemariam, "Modulation of tumour necrosis factor- $\alpha$ induced cytotoxicity by polyphenols," Phytotherapy Research, vol. 11, no. 4, pp. 277-280, 1997.

[103] S. Habtemariam, "Catechols and quercetin reduce MTT through iron ions: a possible artefact in cell viability assays," Phytotherapy Research, vol. 9, no. 8, pp. 603-605, 1995.

[104] S. Habtemariam, "Activity-guided isolation and identification of free radical-scavenging components from ethanolic extract of boneset (leaves of Eupatorium perfoliatum)," Natural Product Communications, vol. 3, no. 8, pp. 1317-1320, 2008.

[105] S. Habtemariam and R. A. Cowley, "Antioxidant and anti$\alpha$-glucosidase compounds from the rhizome of peltiphyllum peltatum (Torr.) Engl," Phytotherapy Research, vol. 26, no. 11, pp. 1656-1660, 2012.

[106] S. Habtemariam and G. K. Varghese, "A novel diterpene skeleton: identification of a highly aromatic, cytotoxic and antioxidant 5-methyl-10-demethyl-abietane-type diterpene from Premna serratifolia," Phytotherapy Research, vol. 29, no. 1, pp. 80-85, 2015.

[107] L. V. Bose, G. K. Varghese, and S. Habtemariam, "Identification of acteoside as the active antioxidant principle of Premna serratifolia root wood tissues," Phytopharmacology, vol. 4, no. 2, pp. 228-236, 2013.

[108] S. Habtemariam, "Protective Effects of Caffeic Acid and the Alzheimer's Brain: An Update," Mini-Reviews in Medicinal Chemistry, vol. 17, no. 8, pp. 667-674, 2017. 
[109] D. Li, W. W. Yang, and R. Cai, "Protective effects of cistanche total glycosides on dopaminergic neuron in substantia nigra of model mice of Parkinson's disease," Chinese Journal of Integrated Traditional and Western Medicine, vol. 28, no. 3, pp. 248-251, 2008.

[110] Y. Gao and X.-P. Pu, "Neuroprotective effect of acteoside against rotenone-induced damage of SH-SY5Y cells and its possible mechanism," Chinese Pharmacological Bulletin, vol. 23, no. 2, pp. 161-165, 2007.

[111] J. Y. Lee, E.-R. Woo, and K. W. Kang, "Inhibition of lipopolysaccharide-inducible nitric oxide synthase expression by acteoside through blocking of AP-1 activation," Journal of Ethnopharmacology, vol. 97, no. 3, pp. 561-566, 2005.

[112] X. P. Zhao and L. Pu, "Neuroprotective effect of acteoside against MPTP-induced mouse model of Parkinsons disease," Chinese Pharmacological Bulletin, vol. 23, pp. 42-46, 2007.

[113] H. Chen, F. C. Jing, C. L. Li, P. F. Tu, Q. S. Zheng, and Z. H. Wang, "Echinacoside prevents the striatal extracellular levels of monoamine neurotransmitters from diminution in 6hydroxydopamine lesion rats," Journal of Ethnopharmacology, vol. 114, no. 3, pp. 285-289, 2007.

[114] X. Geng, X. Tian, P. Tu, and X. Pu, "Neuroprotective effects of echinacoside in the mouse MPTP model of Parkinson's disease," European Journal of Pharmacology, vol. 564, no. 1-3, pp. 66-74, 2007.

[115] Q. Zhao, J. Gao, W. Li, and D. Cai, "Neurotrophic and neurorescue effects of Echinacoside in the subacute MPTP mouse model of Parkinson's disease," Brain Research, vol. 1346, pp. 224-236, 2010.

[116] G. Oboh, O. M. Agunloye, A. J. Akinyemi, A. O. Ademiluyi, and S. A. Adefegha, "Comparative study on the inhibitory effect of caffeic and chlorogenic acids on key enzymes linked to Alzheimer's disease and some pro-oxidant induced oxidative stress in rats' brain-in vitro," Neurochemical Research, vol. 38, no. 2, pp. 413-419, 2013.

[117] C.-F. Tsai, Y.-H. Kuo, W.-L. Yeh et al., "Regulatory effects of caffeic acid phenethyl ester on neuroinflammation in microglial cells," International Journal of Molecular Sciences, vol. 16, no. 3, pp. 5572-5589, 2015.

[118] J.-K. Kim and H.-D. Jang, "Nrf2-mediated HO-1 induction coupled with the ERK signaling pathway contributes to indirect antioxidant capacity of caffeic acid phenethyl ester in HepG2 cells," International Journal of Molecular Sciences, vol. 15, no. 7, pp. 12149-12165, 2014.

[119] S. Habtemariam and A. Belai, "Natural Therapies of the Inflammatory Bowel Disease: The Case of Rutin and its Aglycone, Quercetin," Mini-Reviews in Medicinal Chemistry, vol. 17, no. 999, pp. 1-10, 2017.

[120] S. F. Nabavi, S. Habtemariam, M. Jafari, A. Sureda, and S. M. Nabavi, "Protective role of gallic acid on sodium fluoride induced oxidative stress in rat brain," Bulletin of Environmental Contamination and Toxicology, vol. 89, no. 1, pp. 73-77, 2012.

[121] S. F. Nabavi, S. M. Nabavi, S. Habtemariam, A. H. Moghaddam, A. Sureda, and M. Mirzaei, "Neuroprotective effects of methyl3-O-methyl gallate against sodium fluoride-induced oxidative stress in the brain of rats," Cellular and Molecular Neurobiology, vol. 33, no. 2, pp. 261-267, 2013.

[122] S. F. Nabavi, S. Habtemariam, A. Di Lorenzo et al., "Post-stroke depression modulation and in vivo antioxidant activity of gallic acid and its synthetic derivatives in a murine model system," Nutrients, vol. 8, no. 5, article no. 248, 2016.
[123] V. Curti, E. Capelli, F. Boschi et al., "Modulation of human miR17-3p expression by methyl 3-O-methyl gallate as explanation of its in vivo protective activities," Molecular Nutrition and Food Research, vol. 58, no. 9, pp. 1776-1784, 2014.

[124] H. An, I. S. Kim, S. Koppula et al., "Protective effects of Gastrodia elata Blume on $\mathrm{MPP}^{+}$-induced cytotoxicity in human dopaminergic SH-SY5Y cells," Journal of Ethnopharmacology, vol. 130, no. 2, pp. 290-298, 2010.

[125] H. Kumar, I.-S. Kim, S. V. More, B.-W. Kim, Y.-Y. Bahk, and D.K. Choi, "Gastrodin protects apoptotic dopaminergic neurons in a toxin-induced Parkinson's disease model," Evidence-Based Complementary and Alternative Medicine, vol. 2013, Article ID 514095, 13 pages, 2013.

[126] J.-N. Dai, Y. Zong, L.-M. Zhong et al., "Gastrodin inhibits expression of inducible no synthase, cyclooxygenase-2 and proinflammatory cytokines in cultured LPS-stimulated microglia via MAPK pathways," PLoS ONE, vol. 6, no. 7, Article ID e21891, 2011.

[127] S. F. Nabavi, M. Daglia, A. H. Moghaddam, S. Habtemariam, and S. M. Nabavi, "Curcumin and liver disease: From chemistry to medicine," Comprehensive Reviews in Food Science and Food Safety, vol. 13, no. 1, pp. 62-77, 2014.

[128] A. Marchiani, C. Rozzo, A. Fadda, G. Delogu, and P. Ruzza, "Curcumin and curcumin-like molecules: from spice to drugs," Current medicinal chemistry, vol. 21, no. 2, pp. 204-222, 2014.

[129] R. P. Ojha, M. Rastogi, B. P. Devi, A. Agrawal, and G. P. Dubey, "Neuroprotective effect of curcuminoids against inflammationmediated dopaminergic neurodegeneration in the mptp model of parkinson's Disease," Journal of Neuroimmune Pharmacology, vol. 7, no. 3, pp. 609-618, 2012.

[130] J. Pan, H. Li, J.-F. Ma et al., "Curcumin inhibition of JNKs prevents dopaminergic neuronal loss in a mouse model of Parkinson's disease through suppressing mitochondria dysfunction," Translational Neurodegeneration, vol. 1, p. 16, 2012.

[131] W. Tripanichkul and E.-O. Jaroensuppaperch, "Curcumin protects nigrostriatal dopaminergic neurons and reduces glial activation in 6-hydroxydopamine hemiparkinsonian mice model," International Journal of Neuroscience, vol. 122, no. 5, pp. 263270, 2012.

[132] T.-F. Jiang, Y.-J. Zhang, H.-Y. Zhou et al., "Curcumin ameliorates the neurodegenerative pathology in A53T $\alpha$-synuclein cell model of Parkinson's disease through the downregulation of mTOR/p70S6K signaling and the recovery of macroautophagy," Journal of Neuroimmune Pharmacology, vol. 8, no. 1, pp. 356369, 2013.

[133] M. S. Wang, S. Boddapati, S. Emadi, and M. R. Sierks, "Curcumin reduces $\alpha$-synuclein induced cytotoxicity in Parkinson's disease cell model," BMC Neuroscience, vol. 11, article no. 57, pp. $1-10,2010$.

[134] J. M. Ringman, S. A. Frautschy, G. M. Cole, D. L. Masterman, and J. L. Cummings, "A potential role of the curry spice curcumin in Alzheimer's disease," Current Alzheimer Research, vol. 2, no. 2, pp. 131-136, 2005.

[135] S. Begum, M. R. Jones, G. P. Lim et al., "Curcumin structurefunction, bioavailability, and efficacy in models of neuroinflammation and Alzheimer's disease," Journal of Pharmacology and Experimental Therapeutics, vol. 326, no. 1, pp. 196-208, 2008.

[136] S. Mishra and K. Palanivelu, "The effect of curcumin (turmeric) on Alzheimer's disease: an overview," Annals of Indian Academy of Neurology, vol. 11, no. 1, pp. 13-19, 2008.

[137] B. Ray and D. K. Lahiri, "Neuroinflammation in Alzheimer's disease: different molecular targets and potential therapeutic 
agents including curcumin," Current Opinion in Pharmacology, vol. 9, no. 4, pp. 434-444, 2009.

[138] E. Sikora, G. Scapagnini, and M. Barbagallo, "Curcumin, inflammation, ageing and age-related diseases," Immunity and Ageing, vol. 7, no. 1, p. 1, 2010.

[139] T. Hamaguchi, K. Ono, and M. Yamada, "Curcumin and Alzheimer's disease," CNS Neuroscience and Therapeutics, vol. 16, no. 5, pp. 285-297, 2010.

[140] J. M. Ringman, S. A. Frautschy, E. Teng et al., "Oral curcumin for Alzheimer's disease: tolerability and efficacy in a 24-week randomized, double blind, placebo-controlled study," Alzheimer's Research and Therapy, vol. 4, no. 5, p. 43, 2012.

[141] L. Baum and A. Ng, "Curcumin interaction with copper and iron suggests one possible mechanism of action in Alzheimer's disease animal models," Journal of Alzheimer's Disease, vol. 6, no. 4, pp. 367-377, 2004.

[142] A. Y. Sun, Q. Wang, A. Simonyi, and G. Y. Sun, "Botanical phenolics and brain health," NeuroMolecular Medicine, vol. 10, no. 4, pp. 259-274, 2008.

[143] E. Tellone, A. Galtieri, A. Russo, B. Giardina, and S. Ficarra, "Resveratrol: a focus on several neurodegenerative diseases," Oxidative Medicine and Cellular Longevity, vol. 2015, Article ID 392169, 14 pages, 2015.

[144] A. Y. Sun, Q. Wang, A. Simonyi, and G. Y. Sun, "Resveratrol as a therapeutic agent for neurodegenerative diseases," Molecular Neurobiology, vol. 41, no. 2-3, pp. 375-383, 2010.

[145] T. J. Cohen, J. L. Guo, D. E. Hurtado et al., "The acetylation of tau inhibits its function and promotes pathological tau aggregation," Nature Communications, vol. 2, no. 1, p. 252, 2011.

[146] C. Cantó and J. Auwerx, "Targeting sirtuin 1 to improve metabolism: All you need is NAD+?" Pharmacological Reviews, vol. 64, no. 1, pp. 166-187, 2012.

[147] D. Alvira, M. Yeste-Velasco, J. Folch et al., "Comparative analysis of the effects of resveratrol in two apoptotic models: inhibition of complex I and potassium deprivation in cerebellar neurons," Neuroscience, vol. 147, no. 3, pp. 746-756, 2007.

[148] G. Mazzanti and S. Di Giacomo, "Curcumin and resveratrol in the management of cognitive disorders: What is the clinical evidence?" Molecules, vol. 21, no. 9, article no. 1243, 2016.

[149] T. Ahmed, S. Javed, S. Javed et al., "Resveratrol and Alzheimer's Disease: Mechanistic Insights," Molecular Neurobiology, vol. 54, no. 4, pp. 2622-2635, 2017.

[150] N. Braidy, B.-E. Jugder, A. Poljak et al., "Resveratrol as a potential therapeutic candidate for the treatment and management of alzheimer's disease," Current Topics in Medicinal Chemistry, vol. 16, no. 17, pp. 1951-1960, 2016.

[151] C. Porro, A. Cianciulli, R. Calvello, and M. A. Panaro, "Reviewing the role of resveratrol as a natural modulator of microglial activities," Current Pharmaceutical Design, vol. 21, no. 36, pp. 5277-5291, 2015.

[152] L. Zhang, L. Hao, H. Wang et al., "Neuroprotective Effect of Resveratrol Against Glutamate-Induced Excitotoxicity," Advances in Clinical and Experimental Medicine, vol. 24, no. 1, pp. 161-165, 2015.

[153] T. Ma, M. S. Tan, J. T. Yu, and L. Tan, "Resveratrol as a therapeutic agent for Alzheimer's disease," BioMed Research International, vol. 2014, Article ID 350516, 13 pages, 2014.

[154] S. D. Rege, T. Geetha, G. D. Griffin, T. L. Broderick, and J. R. Babu, "Neuroprotective effects of resveratrol in Alzheimer disease pathology," Frontiers in Aging Neuroscience, vol. 6, article 218, 2014.
[155] X. Mu, G. He, Y. Cheng, X. Li, B. Xu, and G. Du, "Baicalein exerts neuroprotective effects in 6-hydroxydopamine-induced experimental parkinsonism in vivo and in vitro," Pharmacology Biochemistry and Behavior, vol. 92, no. 4, pp. 642-648, 2009.

[156] X.-X. Li, G.-R. He, X. Mu et al., "Protective effects of baicalein against rotenone-induced neurotoxicity in PC12 cells and isolated rat brain mitochondria," European Journal of Pharmacology, vol. 674, no. 2-3, pp. 227-233, 2012.

[157] J.-H. Lu, M. T. Ardah, S. S. K. Durairajan et al., "Baicalein Inhibits Formation of $\alpha$-Synuclein Oligomers within Living Cells and Prevents $\mathrm{A} \beta$ Peptide Fibrillation and Oligomerisation," ChemBioChem, vol. 12, no. 4, pp. 615-624, 2011.

[158] X. Mu, G.-R. He, X. Yuan, X.-X. Li, and G.-H. Du, "Baicalein protects the brain against neuron impairments induced by MPTP in C57BL/6 mice," Pharmacology Biochemistry and Behavior, vol. 98, no. 2, pp. 286-291, 2011.

[159] X. Yu, G.-R. He, L. Sun et al., "Assessment of the treatment effect of baicalein on a model of Parkinsonian tremor and elucidation of the mechanism," Life Sciences, vol. 91, no. 1-2, pp. 5-13, 2012.

[160] Y. Cheng, G. He, X. Mu et al., "Neuroprotective effect of baicalein against MPTP neurotoxicity: Behavioral, biochemical and immunohistochemical profile," Neuroscience Letters, vol. 441, no. 1, pp. 16-20, 2008.

[161] M. R. De Oliveira, S. F. Nabavi, S. Habtemariam, I. Erdogan Orhan, M. Daglia, and S. M. Nabavi, "The effects of baicalein and baicalin on mitochondrial function and dynamics: A review," Pharmacological Research, vol. 100, pp. 296-308, 2015.

[162] Y. Porat, A. Abramowitz, and E. Gazit, "Inhibition of amyloid fibril formation by polyphenols: structural similarity and aromatic interactions as a common inhibition mechanism," Chemical Biology and Drug Design, vol. 67, no. 1, pp. 27-37, 2006.

[163] B. Giunta, D. Obregon, R. Velisetty, P. R. Sanberg, C. V. Borlongan, and J. Tan, "The immunology of traumatic brain injury: a prime target for Alzheimer's disease prevention," Journal of Neuroinflammation, vol. 9, no. 1, article 185, p. 678, 2012.

[164] I. Solanki, P. Parihar, M. L. Mansuri, and M. S. Parihar, "Flavonoid-based therapies in the early management of neurodegenerative diseases," Advances in Nutrition, vol. 6, no. 1, pp. 64-72, 2015.

[165] W. Gu, L.-J. Xu, Z.-Q. Liu et al., “The flavonoid baicalein rescues synaptic plasticity and memory deficits in a mouse model of Alzheimer's disease," Behavioural Brain Research, vol. 311, pp. 309-321, 2016.

[166] A. Di Meco, J. Li, B. E. Blass, M. Abou-Gharbia, E. Lauretti, and D. Praticò, "12/15-Lipoxygenase Inhibition Reverses Cognitive Impairment, Brain Amyloidosis, and Tau Pathology by Stimulating Autophagy in Aged Triple Transgenic Mice," Biological Psychiatry, vol. 81, no. 2, pp. 92-100, 2017.

[167] T. Lin, H. Tsai, C. Lee et al., "An Improved Drugs Screening System Reveals that Baicalein Ameliorates the A $\beta / A M P A / N M D A-$ Induced Depolarization of Neurons," Journal of Alzheimer's Disease, vol. 56, no. 3, pp. 959-976, 2017.

[168] I. C. Martins and N. Ferreira, "Neurocognitive improvement through plant food bioactives: A particular approach to Alzheimer's disease," in Food Bioactives, pp. 267-298, Springer International Publishing, 2017.

[169] J. Shi, G. Wu, X. Zou, and K. Jiang, "Oleuropein Protects Intracerebral Hemorrhage-induced Disruption of Blood-brain Barrier through Alleviation of Oxidative Stress," Pharmacological Reports, 2017. 
[170] L. Janjušević, M. Karaman, F. Šibul et al., “The lignicolous fungus Trametes versicolor (L.) Lloyd (1920): a promising natural source of antiradical and AChE inhibitory agents," Journal of Enzyme Inhibition and Medicinal Chemistry, vol. 32, no. 1, pp. 355-362, 2016.

[171] S. H. Omar, "Biophenols pharmacology against the amyloidogenic activity in Alzheimer's disease," Biomedicine \& Pharmacotherapy, vol. 89, pp. 396-413, 2017.

[172] I. Cruz, P. Puthongking, S. Cravo et al., "Xanthone and Flavone Derivatives as Dual Agents with Acetylcholinesterase Inhibition and Antioxidant Activity as Potential Anti-Alzheimer Agents," Journal of Chemistry, vol. 2017, pp. 1-16, 2017.

[173] B. Zhu, Q. Zhang, J. Wang, and X. Mei, “Cocrystals of Baicalein with Higher Solubility and Enhanced Bioavailability," Crystal Growth \& Design, vol. 17, no. 4, pp. 1893-1901, 2017.

[174] A. Rasul, F. M. Millimouno, W. Ali Eltayb, M. Ali, J. Li, and X. Li, "Pinocembrin: a novel natural compound with versatile pharmacological and biological activities," BioMed Research International, vol. 2013, Article ID 379850, 9 pages, 2013.

[175] L.-L. Shi, G. F. Qiang, M. Gao et al., "Effect of pinocembrin on brain mitochondrial respiratory function," Yao Xue Xue Bao= Acta pharmaceutica Sinica, vol. 46, no. 6, pp. 642-649, 2011.

[176] M. Gao, R. Liu, S. Y. Zhu, and G. H. Du, "Acute neurovascular unit protective action of pinocembrin against permanent cerebral ischemia in rats," Journal of Asian Natural Products Research, vol. 10, no. 6, pp. 551-558, 2008.

[177] R. Liu, M. Gao, Z. Yang, and G. Du, "Pinocembrin protects rat brain against oxidation and apoptosis induced by ischemiareperfusion both in vivo and in vitro," Brain Research, vol. 1216, pp. 104-115, 2008.

[178] H.-M. Guang and G.-H. Du, "Protections of pinocembrin on brain mitochondria contribute to cognitive improvement in chronic cerebral hypoperfused rats," European Journal of Pharmacology, vol. 542, no. 1-3, pp. 77-83, 2006.

[179] L. L. Shi, B. N. Chen, M. Gao et al., "The characteristics of therapeutic effect of pinocembrin in transient global brain ischemia/reperfusion rats," Life Sciences, vol. 88, no. 11-12, pp. 521-528, 2011.

[180] F. Meng, R. Liu, M. Gao et al., "Pinocembrin attenuates blood-brain barrier injury induced by global cerebral ischemiareperfusion in rats," Brain Research, vol. 1391, pp. 93-101, 2011.

[181] A. Sala, M. C. Recio, G. R. Schinella et al., "Assessment of the anti-inflammatory activity and free radical scavenger activity of tiliroside," European Journal of Pharmacology, vol. 461, no. 1, pp. 53-61, 2003.

[182] L. W. Soromou, X. Chu, L. Jiang et al., "In vitro and in vivo protection provided by pinocembrin against lipopolysaccharideinduced inflammatory responses," International Immunopharmacology, vol. 14, no. 1, pp. 66-74, 2012.

[183] P. Tuchinda, V. Reutrakul, P. Claeson et al., "Anti-inflammatory cyclohexenyl chalcone derivatives in Boesenbergia pandurata," Phytochemistry, vol. 59, no. 2, pp. 169-173, 2002.

[184] R. Charoensin, S. Punvittayagul, C. Pompimon, W. Mevateeand, and U. Wongpoomchai, "Toxicological and clastogenic evaluation of pinocembrin and pinostrobin isolated from Boesenbergia pandurata in Wistar rats," Thai Journal of Toxicology, vol. 25, no. 1, pp. 29-40, 2010.

[185] A. Ghanemi, "Alzheimer's disease therapies: Selected advances and future perspectives," Alexandria Journal of Medicine, vol. 51, no. 1, pp. 1-3, 2015.
[186] H. Wang, Y. Miao, A. Z. Mir et al., "Inhibition of beta-amyloidinduced neurotoxicity by pinocembrin through $\mathrm{Nrf} 2 / \mathrm{HO}-1$ pathway in SH-SY5Y cells," Journal of the Neurological Sciences, vol. 368, pp. 223-230, 2016.

[187] N. Zabaiou, A. Fouache, A. Trousson et al., "Biological properties of propolis extracts: Something new from an ancient product," Chemistry and Physics of Lipids, 2017.

[188] S. A. Mandel, T. Amit, L. Kalfon, L. Reznichenko, and M. B. H. Youdim, "Targeting multiple neurodegenerative diseases etiologies with multimodal-acting green tea catechins," Journal of Nutrition, vol. 138, no. 8, pp. 1578S-1583S, 2008.

[189] O. Weinreb, T. Amit, S. Mandel, and M. B. H. Youdim, "Neuroprotective molecular mechanisms of (-)-epigallocatechin-3gallate: a reflective outcome of its antioxidant, iron chelating and neuritogenic properties," Genes and Nutrition, vol. 4, no. 4, pp. 283-296, 2009.

[190] B. A. Sutherland, O. M. Shaw, A. N. Clarkson, D. M. Jackson, I. A. Sammut, and I. Appleton, "Neuroprotective effects of (-)epigallocatechin gallate following hypoxia-ischemia-induced brain damage: novel mechanisms of action," The FASEB Journal, vol. 19, no. 2, pp. 258-260, 2005.

[191] O. Aktas, T. Prozorovski, A. Smorodchenko et al., "Green Tea Epigallocatechin-3-Gallate Mediates T Cellular NF- $\kappa$ B Inhibition and Exerts Neuroprotection in Autoimmune Encephalomyelitis," The Journal of Immunology, vol. 173, no. 9, pp. 5794-5800, 2004.

[192] Y. Levites, O. Weinreb, G. Maor, M. B. H. Youdim, and S. Mandel, "Green tea polyphenol (-)-epigallocatechin-3-gallate prevents $N$-methyl-4-phenyl-1,2,3,6-tetrahydropyridine-induced dopaminergic neurodegeneration," Journal of Neurochemistry, vol. 78, no. 5, pp. 1073-1082, 2001.

[193] K. Rezai-Zadeh, D. Shytle, N. Sun et al., "Green tea epigallocatechin-3-gallate (EGCG) modulates amyloid precursor protein cleavage and reduces cerebral amyloidosis in Alzheimer transgenic mice," Journal of Neuroscience, vol. 25, no. 38, pp. 8807-8814, 2005.

[194] Y. Levites, T. Amit, M. B. H. Youdim, and S. Mandel, "Involvement of protein kinase $\mathrm{C}$ activation and cell survival/cell cycle genes in green tea polyphenol (-)-epigallocatechin 3-gallate neuroprotective action," The Journal of Biological Chemistry, vol. 277, no. 34, pp. 30574-30580, 2002.

[195] J. Y. Ban, S.-Y. Jeon, K. Bae, K.-S. Song, and Y. H. Seong, "Catechin and epicatechin from Smilacis chinae rhizome protect cultured rat cortical neurons against amyloid $\beta$ protein (25-35)induced neurotoxicity through inhibition of cytosolic calcium elevation," Life Sciences, vol. 79, no. 24, pp. 2251-2259, 2006.

[196] P. Hajieva, "The Effect of Polyphenols on Protein Degradation Pathways: Implications for Neuroprotection," Molecules, vol. 22, no. 1, p. 159, 2017.

[197] L. Xicota, J. Rodriguez-Morato, M. Dierssen, and R. de la Torre, "Potential Role of (-)-Epigallocatechin-3-Gallate (EGCG) in the Secondary Prevention of Alzheimer Disease," Current Drug Targets, vol. 18, no. 2, pp. 174-195, 2016.

[198] K. H. Seo, D. Y. Lee, R. H. Jeong et al., "Neuroprotective effect of prenylated arylbenzofuran and flavonoids from Morus alba fruits on glutamateinduced oxidative injury in HT22 hippocampal cells," Journal of Medicinal Food, vol. 18, no. 4, pp. 403-408, 2015.

[199] S. Habtemariam, "Rutin as a natural therapy for Alzheimer's disease: insights into its mechanisms of action," Current Medicinal Chemistry, vol. 23, no. 9, pp. 860-873, 2016. 
[200] J. Wu, L. Maoqiang, H. Fan et al., "Rutin attenuates neuroinflammation in spinal cord injury rats," Journal of Surgical Research, vol. 203, no. 2, pp. 331-337, 2016.

[201] C. Regitz, L. M. Dußling, and U. Wenzel, "Amyloid-beta (A $\beta 1-$ 42)-induced paralysis in Caenorhabditis elegans is inhibited by the polyphenol quercetin through activation of protein degradation pathways," Molecular Nutrition \& Food Research, vol. 58, no. 10, pp. 1931-1940, 2014.

[202] L. Qu, X. C. Liang, B. Gu, and W. Liu, "Quercetin alleviates high glucose-induced Schwann cell damage by autophagy," Neural Regeneration Research, vol. 9, no. 12, pp. 1195-1203, 2014.

[203] W. Li, D. Li, S. Zhao et al., "Rutin attenuates isofluraneinduced neuroapoptosis via modulating JNK and p38 MAPK pathways in the hippocampi of neonatal rats," Experimental and Therapeutic Medicine, vol. 1, pp. 19-20, 2017.

[204] G. Ramalingayya, S. P. Cheruku, P. Nayak et al., "Rutin protects against neuronal damage in vitro and ameliorates doxorubicininduced memory deficits in vivo in Wistar rats," Drug Design, Development and Therapy, vol. 11, pp. 1011-1026, 2017.

[205] R. Banerjee, "Effect of polyphenols on protein misfolding," in Neuroprotective Effects of Phytochemicals in Neurological Disorders, pp. 501-513, John Wiley \& Sons, Inc., 2017.

[206] Y. Chang, C.-Y. Hsieh, Z.-A. Peng et al., "Neuroprotective mechanisms of puerarin in middle cerebral artery occlusioninduced brain infarction in rats," Journal of Biomedical Science, vol. 16, p. 9, 2009.

[207] R.-M. Han, Y.-X. Tian, E. M. Becker, M. L. Andersen, J.-P. Zhang, and L. H. Skibsted, "Puerarin and conjugate bases as radical scavengers and antioxidants: Molecular mechanism and synergism with $\beta$-carotene," Journal of Agricultural and Food Chemistry, vol. 55, no. 6, pp. 2384-2391, 2007.

[208] G. Zhu, X. Wang, S. Wu, and Q. Li, "Involvement of activation of $\mathrm{PI} 3 \mathrm{~K} / \mathrm{Akt}$ pathway in the protective effects of puerarin against $\mathrm{MPP}^{+}$-induced human neuroblastoma SH-SY5Y cell death," Neurochemistry International, vol. 60, no. 4, pp. 400-408, 2012.

[209] Y.-F. Cheng, G.-Q. Zhu, M. Wang et al., "Involvement of ubiquitin proteasome system in protective mechanisms of Puerarin to MPP+-elicited apoptosis," Neuroscience Research, vol. 63, no. 1, pp. 52-58, 2009.

[210] G. Zheng, C. Yu, and Z. Yang, "Puerarin suppresses production of nitric oxide and inducible nitric oxide synthase in lipopolysaccharide-induced N9 microglial cells through regulating MAPK phosphorylation, O-GlcNAcylation and NF- $\kappa \mathrm{B}$ translocation," International Journal of Oncology, vol. 40, no. 5, pp. 1610-1618, 2012.

[211] G. Wang, L. Zhou, Y. Zhang et al., "Implication of the c-Jun$\mathrm{NH} 2$-terminal kinase pathway in the neuroprotective effect of puerarin against 1-methyl-4-phenylpyridinium $\left(\mathrm{MPP}^{+}\right)$induced apoptosis in PC-12 cells," Neuroscience Letters, vol. 487, no. 1, pp. 88-93, 2011.

[212] R. Li, T. Liang, L. Xu, N. Zheng, K. Zhang, and X. Duan, "Puerarin attenuates neuronal degeneration in the substantia nigra of 6-OHDA-lesioned rats through regulating BDNF expression and activating the Nrf2/ARE signaling pathway," Brain Research, vol. 1523, pp. 1-9, 2013.

[213] G. Zhu, X. Wang, Y. Chen et al., "Puerarin protects dopaminergic neurons against 6-hydroxydopamine neurotoxicity via inhibiting apoptosis and upregulating glial cell line-derived neurotrophic factor in a rat model of Parkinson's disease," Planta Medica, vol. 76, no. 16, pp. 1820-1826, 2010.

[214] Y. Zhou, N. Xie, L. Li, Y. Zou, X. Zhang, and M. Dong, "Puerarin alleviates cognitive impairment and oxidative stress in APP/PS1 transgenic mice," International Journal of Neuropsychopharmacology, vol. 17, no. 4, pp. 635-644, 2014.

[215] H. Zhang, Y. Liu, M. Lao, Z. Ma, and X. Yi, "Puerarin protects Alzheimer's disease neuronal cybrids from oxidant-stress induced apoptosis by inhibiting pro-death signaling pathways," Experimental Gerontology, vol. 46, no. 1, pp. 30-37, 2011.

[216] L. Li, Z. Xue, L. Chen, X. Chen, H. Wang, and X. Wang, "Puerarin suppression of A $\beta 1-42$-induced primary cortical neuron death is largely dependent on ER $\beta$," Brain Research, vol. 1657, pp. 87-94, 2017.

[217] L. Wu, T. Tong, S. Wan et al., "Protective Effects of Puerarin against $\mathrm{A} \beta$ 1-42-Induced Learning and Memory Impairments in Mice," Planta Medica, vol. 83, no. 03/04, pp. 224-231, 2017.

[218] S.-S. Zhao, W.-N. Yang, H. Jin, K.-G. Ma, and G.-F. Feng, "Puerarin attenuates learning and memory impairments and inhibits oxidative stress in STZ-induced SAD mice," NeuroToxicology, vol. 51, pp. 166-171, 2015.

[219] H. Tang, X. Song, Y. Ling et al., "Puerarin attenuates myocardial hypoxia/reoxygenation injury by inhibiting autophagy via the Akt signaling pathway," Molecular Medicine Reports, vol. 15, no. 6, pp. 3747-3754, 2017.

[220] S. F. Nabavi, N. Braidy, S. Habtemariam, A. Sureda, A. Manayi, and S. M. Nabavi, "Neuroprotective effects of fisetin in alzheimer's and parkinson's diseases: From chemistry to medicine," Current Topics in Medicinal Chemistry, vol. 16, no. 17, pp. 1910-1915, 2016.

[221] S. F. Nabavi, N. Braidy, S. Habtemariam et al., "Neuroprotective effects of chrysin: from chemistry to medicine," Neurochemistry International, vol. 90, pp. 224-231, 2015.

[222] M. T. H. Khan, I. Orhan, F. S. Şenol et al., "Cholinesterase inhibitory activities of some flavonoid derivatives and chosen xanthone and their molecular docking studies," ChemicoBiological Interactions, vol. 181, no. 3, pp. 383-389, 2009.

[223] E. Abbasi, M. Nassiri-Asl, M. Shafeei, and M. Sheikhi, "Neuroprotective effects of vitexin, a flavonoid, on pentylenetetrazoleinduced seizure in rats," Chemical Biology and Drug Design, vol. 80, no. 2, pp. 274-278, 2012.

[224] I. E. Orhan, M. Daglia, S. F. Nabavi, M. R. Loizzo, E. SobarzoSánchez, and S. M. Nabavi, "Flavonoids and dementia: An update," Current Medicinal Chemistry, vol. 22, no. 8, pp. 10041015, 2015.

[225] A. Justin Thenmozhi, T. R. W. Raja, U. Janakiraman, and T. Manivasagam, "Erratum to: Neuroprotective Effect of Hesperidin on Aluminium Chloride Induced Alzheimer's Disease in Wistar Rats," Neurochemical Research, vol. 40, no. 9, p. 2006, 2015.

[226] Y. Liu, L. Zhang, and J. Liang, "Activation of the Nrf2 defense pathway contributes to neuroprotective effects of phloretin on oxidative stress injury after cerebral ischemia/reperfusion in rats," Journal of the Neurological Sciences, vol. 351, no. 1-2, pp. 88-92, 2015.

[227] M. T. Islam, C. B. Da Silva, M. V. O. B. De Alencar, M. F. C. J. Paz, F. R. D. C. Almeida, and A. A. D. C. MeloCavalcante, "Diterpenes: Advances in Neurobiological Drug Research," Phytotherapy Research, vol. 30, no. 6, pp. 915-928, 2016.

[228] S. Habtemariam, "The Therapeutic Potential of Rosemary (Rosmarinus officinalis) Diterpenes for Alzheimer's Disease," Evidence-Based Complementary and Alternative Medicine, vol. 2016, Article ID 2680409, 14 pages, 2016.

[229] D. Zhang, B. Lee, A. Nutter et al., "Protection from cyanideinduced brain injury by the Nrf2 transcriptional activator 
carnosic acid," Journal of Neurochemistry, vol. 133, no. 6, pp. 898-908, 2015.

[230] S.-J. Kim, J.-S. Kim, H.-S. Cho et al., "Carnosol, a component of rosemary (Rosmarinus officinalis L.) protects nigral dopaminergic neuronal cells," NeuroReport, vol. 17, no. 16, pp. 1729-1733, 2006.

[231] C.-W. Hou, Y.-T. Lin, Y.-L. Chen et al., "Neuroprotective effects of carnosic acid on neuronal cells under ischemic and hypoxic stress," Nutritional Neuroscience, vol. 15, no. 6, pp. 257-263, 2012.

[232] Z. Hui-Hui, T. Peng-Fei, Z. Kan, W. Hui, W. Bao-Huai, and L. Jing-Fen, "Antioxidant properties of phenolic diterpenes from Rosmarinus officinalis," Acta Pharmacologica Sinica, vol. 22, no. 12, pp. 1094-1098, 2001.

[233] S. Samman, B. Sandström, M. B. Toft et al., "Green tea or rosemary extract added to foods reduces nonheme-iron absorption1,2,3," American Journal of Clinical Nutrition, vol. 73, no. 3, pp. 607-612, 2001.

[234] K.-C. Lian, J.-J. Chuang, C.-W. Hsieh et al., "Dual mechanisms of NF- $\kappa \mathrm{B}$ inhibition in carnosol-treated endothelial cells," Toxicology and Applied Pharmacology, vol. 245, no. 1, pp. 21-35, 2010.

[235] R. Foresti, S. K. Bains, T. S. Pitchumony et al., "Small molecule activators of the Nrf2-HO-1 antioxidant axis modulate heme metabolism and inflammation in BV2 microglia cells," Pharmacological Research, vol. 76, pp. 132-148, 2013.

[236] D. Poeckel, C. Greiner, M. Verhoff et al., "Carnosic acid and carnosol potently inhibit human 5-lipoxygenase and suppress pro-inflammatory responses of stimulated human polymorphonuclear leukocytes," Biochemical Pharmacology, vol. 76, no. 1, pp. 91-97, 2008.

[237] P. Meng, H. Yoshida, T. Matsumiya et al., "Carnosic acid suppresses the production of amyloid- $\beta 1-42$ by inducing the metalloprotease gene TACE/ADAM17 in SH-SY5Y human neuroblastoma cells," Neuroscience Research, vol. 75, no. 2, pp. 94-102, 2013.

[238] H. Yoshida, P. Meng, T. Matsumiya et al., "Carnosic acid suppresses the production of amyloid- $\beta$ 1-42 and 1-43 by inducing an $\alpha$-secretase TACE/ADAM17 in U373MG human astrocytoma cells," Neuroscience Research, vol. 79, no. 1, pp. 8393, 2014.

[239] D. Szwajgier, "Anticholinesterase activity of phenolic acids and their derivatives," Zeitschrift für Naturforschung C, vol. 68, no. 3-4, pp. 125-132, 2013.

[240] M. Merad, W. Soufi, S. Ghalem et al., "Molecular interaction of acetylcholinesterase with carnosic acid derivatives: a neuroinformatics study," CNS \& Neurological Disorders-Drug Targets, vol. 13, no. 3, pp. 440-446, 2014.

[241] N. Azad, H. Rasoolijazi, M. T. Joghataie, and S. Soleimani, "Neuroprotective effects of Carnosic acid in an experimental model of Alzheimer's disease in rats," Cell Journal, vol. 13, no. 1, pp. 39-44, 2011.

[242] H. Rasoolijazi, N. Azad, M. T. Joghataei, M. Kerdari, F. Nikbakht, and M. Soleimani, "The protective role of carnosic acid against beta-amyloid toxicity in rats," The Scientific World Journal, vol. 2013, Article ID 917082, 5 pages, 2013.

[243] G. Topcu and T. Kusman, "Lamiaceae Family Plants as a Potential Anticholinesterase Source in the Treatment of Alzheimer's Disease," Bezmialem Science, vol. 2, no. 1, pp. 1-25, 2014.

[244] A. L. Harvey, "The pharmacology of galanthamine and its analogues," Pharmacology and Therapeutics, vol. 68, no. 1, pp. 113-128, 1995.
[245] T. Thomsen, U. Bickel, J. P. Fischer, and H. Kewitz, "Galanthamine hydrobromide in a long-term treatment of alzheimer's disease," Dementia and Geriatric Cognitive Disorders, vol. 1, no. 1, pp. 46-51, 1990.

[246] J. Olin and L. Schneider, "Galantamine for Alzheimer's disease," Cochrane Database of Systematic Reviews, no. 3, p. CD001747, 2002.

[247] Y. Ago, K. Koda, K. Takuma, and T. Matsuda, "Pharmacological aspects of the acetylcholinesterase inhibitor galantamine," Journal of Pharmacological Sciences, vol. 116, no. 1, pp. 6-17, 2011.

[248] Y. Takada-Takatori, T. Kume, M. Sugimoto et al., "Neuroprotective effects of galanthamine and tacrine against glutamate neurotoxicity," European Journal of Pharmacology, vol. 549, no. 1-3, pp. 19-26, 2006.

[249] Y. Takatori, "Mechanisms of neuroprotective effects of therapeutic acetylcholinesterase inhibitors used in treatment of Alzheimer's disease," Yakugaku Zasshi, vol. 126, no. 8, pp. 607616, 2006.

[250] A. Akaike, Y. Takada-Takatori, T. Kume, and Y. Izumi, "Mechanisms of neuroprotective effects of nicotine and acetylcholinesterase inhibitors: Role of $\alpha 4$ and $\alpha 7$ receptors in neuroprotection," Journal of Molecular Neuroscience, vol. 40, no. 1-2, pp. 211-216, 2010.

[251] A. Proudfoot, "The early toxicology of physostigmine: A tale of beans, great men and egos," Toxicological Reviews, vol. 25, no. 2, pp. 99-138, 2006.

[252] S. Chitnis and J. Rao, "Rivastigmine in Parkinson's disease dementia," Expert Opinion on Drug Metabolism and Toxicology, vol. 5, no. 8, pp. 941-955, 2009.

[253] S. K. Kulkarni and A. Dhir, "Berberine: a plant alkaloid with therapeutic potential for central nervous system disorders," Phytotherapy Research, vol. 24, no. 3, pp. 317-324, 2010.

[254] S. Habtemariam, "The therapeutic potential of Berberis darwinii Stem-bark: Quantification of berberine and in vitro evidence for Alzheimer's disease therapy," Natural Product Communications, vol. 6, no. 8, pp. 1089-1090, 2011.

[255] H. Chu, G. Jin, E. Friedman, and X. Zhen, "Recent development in studies of tetrahydroprotoberberines: mechanism in antinociception and drug addiction," Cellular and Molecular Neurobiology, vol. 28, no. 4, pp. 491-499, 2008.

[256] F. Zhu and C. Qian, "Berberine chloride can ameliorate the spatial memory impairment and increase the expression of interleukin-1 beta and inducible nitric oxide synthase in the rat model of Alzheimer's disease," BMC Neuroscience, vol. 7, p. 78, 2006.

[257] M. Asai, N. Iwata, A. Yoshikawa et al., "Berberine alters the processing of Alzheimer's amyloid precursor protein to decrease $\mathrm{A} \beta$ secretion," Biochemical and Biophysical Research Communications, vol. 352, no. 2, pp. 498-502, 2007.

[258] K. Ingkaninan, P. Phengpa, S. Yuenyongsawad, and N. Khorana, "Acetylcholinesterase inhibitors from Stephania venosa tuber," Journal of Pharmacy and Pharmacology, vol. 58, no. 5, pp. 695700, 2006.

[259] M. Roselli, M. M. Cavalluzzi, C. Bruno et al., "Synthesis and evaluation of berberine derivatives and analogs as potential antiacetylcholinesterase and antioxidant agents," Phytochemistry Letters, vol. 18, pp. 150-156, 2016.

[260] K. Yoo, I. K. Hwang, J. D. Kim et al., "Antiinflammatory effect of the ethanol extract of Berberis koreana in a gerbil model of cerebral ischemia/reperfusion," Phytotherapy Research, vol. 22, no. 11, pp. 1527-1532, 2008. 
[261] K. Yoo, I. K. Hwang, B. O. Lim et al., "Berberry extract reduces neuronal damage and $\mathrm{N}$-methyl-D-aspartate receptor 1 immunoreactivity in the gerbil hippocampus after transient forebrain ischemia," Biological and Pharmaceutical Bulletin, vol. 29, no. 4, pp. 623-628, 2006.

[262] S. Habtemariam, "Berberine and inflammatory bowel disease: A concise review," Pharmacological Research, vol. 113, pp. 592599, 2016.

[263] M. Roselli, M. M. Cavalluzzi, C. Bruno et al., "Synthesis and evaluation of berberine derivatives and analogues as potential anti-acetylcholinesterase and antioxidant agents," Phytochemistry Letters, vol. 18, pp. 150-156, 2016.

[264] I. K. Hwang, K.-Y. Yoo, H. Li et al., "Indole-3-propionic acid attenuates neuronal damage and oxidative stress in the ischemic hippocampus," Journal of Neuroscience Research, vol. 87, no. 9, pp. 2126-2137, 2009.

[265] E. Martinez, F. Artigas, C. Suñol, J. M. Tusell, and E. Gelpi, "Liquid-chromatographic determination of indole-3-acetic acid and 5-hydroxyindole-3-acetic acid in human plasma," Clinical Chemistry, vol. 29, no. 7, pp. 1354-1357, 1983.

[266] W. R. Wikoff, A. T. Anfora, and J. Liu, "Metabolomics analysis reveals large effects of gut microflora on mammalian blood metabolites," Proceedings of the National Academy of Sciences of the United States of America, vol. 106, no. 10, pp. 3698-3703, 2009.

[267] Y.-J. Chyan, B. Poeggeler, R. A. Omar et al., "Potent neuroprotective properties against the Alzheimer $\beta$-amyloid by an endogenous melatonin-related indole structure, indole-3propionic acid," The Journal of Biological Chemistry, vol. 274, no. 31, pp. 21937-21942, 1999.

[268] S. Hu, R. Han, S. Mak, and Y. Han, "Protection against 1-methyl4-phenylpyridinium ion $\left(\mathrm{MPP}^{+}\right)$-induced apoptosis by water extract of ginseng (Panax ginseng C.A. Meyer) in SH-SY5Y cells," Journal of Ethnopharmacology, vol. 135, no. 1, pp. 34-42, 2011.

[269] Q. Liu, J.-P. Kou, and B.-Y. Yu, "Ginsenoside Rg1 protects against hydrogen peroxide-induced cell death in PC12 cells via inhibiting NF- $\kappa$ B activation," Neurochemistry International, vol. 58, no. 1, pp. 119-125, 2011.

[270] H. Xu, H. Jiang, J. Wang, and J. Xie, "Rg1 protects ironinduced neurotoxicity through antioxidant and iron regulatory proteins in 6-OHDA-treated MES23.5 cells," Journal of Cellular Biochemistry, vol. 111, no. 6, pp. 1537-1545, 2010.

[271] H. Xu, H. Jiang, J. Wang, and J. Xie, "Rg1 protects the MPP+treated MES23.5 cells via attenuating DMT1 up-regulation and cellular iron uptake," Neuropharmacology, vol. 58, no. 2, pp. 488-494, 2010.

[272] J. Wang, H.-M. Xu, H.-D. Yang, X.-X. Du, H. Jiang, and J.-X. Xie, "Rg1 reduces nigral iron levels of MPTP-treated C57BL6 mice by regulating certain iron transport proteins," Neurochemistry International, vol. 54, no. 1, pp. 43-48, 2009.

[273] L. Xu, W. F. Chen, and M. S. Wong, "Ginsenoside Rg1 protects dopaminergic neurons in a rat model of Parkinson's disease through the IGF-I receptor signalling pathway," British Journal of Pharmacology, vol. 158, no. 3, pp. 738-748, 2009.

[274] W. X. Xu, L. Liu, L. X. Chen, W. F. Xie, and J. X. Huang, "The protective effect of ginsenoside Rg1 on dopaminergic neurons of substantia in the ovariectomized rat model of Parkinson's disease," Zhongguo ying yong sheng li xue za zhi = Chinese Journal of Applied Physiology, vol. 24, pp. 1-5, 2008.
[275] J.-F. Hu, X.-Y. Song, S.-F. Chu et al., "Inhibitory effect of ginsenoside Rg1 on lipopolysaccharide-induced microglial activation in mice," Brain Research, vol. 1374, pp. 8-14, 2011.

[276] F.-C. Luo, S.-D. Wang, K. Li, H. Nakamura, J. Yodoi, and J. Bai, "Panaxatriol saponins extracted from Panax notoginseng induces thioredoxin-1 and prevents 1-methyl4-phenylpyridinium ion-induced neurotoxicity," Journal of Ethnopharmacology, vol. 127, no. 2, pp. 419-423, 2010.

[277] F.-C. Luo, S.-D. Wang, L. Qi, J.-Y. Song, T. Lv, and J. Bai, "Protective effect of panaxatriol saponins extracted from Panax notoginseng against MPTP-induced neurotoxicity in vivo," Journal of Ethnopharmacology, vol. 133, no. 2, pp. 448-453, 2011.

[278] C.-L. Xie, J.-H. Li, W.-W. Wang, G.-Q. Zheng, and L.-X. Wang, "Neuroprotective effect of ginsenoside-Rg1 on cerebral ischemia/reperfusion injury in rats by downregulating protease-activated receptor-1 expression," Life Sciences, vol. 121, pp. 145-151, 2015.

[279] Y.-F. Zhang, X.-J. Fan, X. Li et al., "Ginsenoside Rg1 protects neurons from hypoxic-ischemic injury possibly by inhibiting $\mathrm{Ca} 2+$ influx through NMDA receptors and L-type voltagedependent Ca2+ channels," European Journal of Pharmacology, vol. 586, no. 1-3, pp. 90-99, 2008.

[280] J. Liu, J. He, L. Huang, L. Dou, S. Wu, and Q. L. Yuan, "Neuroprotective effects of ginsenoside Rbl on hippocampal neuronal injury and neurite outgrowth," Neural Regeneration Research, vol. 9, no. 9, pp. 943-950, 2014.

[281] J. Ma, J. Liu, Q. Wang, H. Yu, Y. Chen, and L. Xiang, “The beneficial effect of ginsenoside Rg1 on Schwann cells subjected to hydrogen peroxide induced oxidative injury," International Journal of Biological Sciences, vol. 9, no. 6, pp. 624-636, 2013.

[282] A. Scholey, A. Ossoukhova, L. Owen et al., "Effects of American ginseng (Panax quinquefolius) on neurocognitive function: an acute, randomised, double-blind, placebo-controlled, crossover study," Psychopharmacology, vol. 212, no. 3, pp. 345-356, 2010.

[283] I. Smith, E. M. Williamson, S. Putnam, J. Farrimond, and B. J. Whalley, "Effects and mechanisms of ginseng and ginsenosides on cognition," Nutrition Reviews, vol. 72, no. 5, pp. 319-333, 2014.

[284] Z. Liang, F. Shi, Y. Wang et al., "Neuroprotective effects of tenuigenin in a SH-SY5Y cell model with 6-OHDA-induced injury," Neuroscience Letters, vol. 497, no. 2, pp. 104-109, 2011.

[285] H.-L. Yuan, B. Li, J. Xu et al., “Tenuigenin Protects Dopaminergic Neurons from Inflammation-Mediated Damage Induced by the Lipopolysaccharide," CNS Neuroscience and Therapeutics, vol. 18, no. 7, pp. 584-590, 2012.

[286] X. Wang, M. Li, Y. Cao et al., "Tenuigenin inhibits LPSinduced inflammatory responses in microglia via activating the Nrf2-mediated HO-1 signaling pathway," European Journal of Pharmacology, vol. 809, pp. 196-202, 2017.

[287] L. Lu, X. Li, P. Xu, Y. Zheng, and X. Wang, “Tenuigenin downregulates the release of nitric oxide, matrix metalloproteinase- 9 and cytokines from lipopolysaccharide-stimulated microglia," Neuroscience Letters, vol. 650, pp. 82-88, 2017.

[288] J. Krieglstein, F. Ausmeier, H. El-Abhar et al., "Neuroprotective effects of Ginkgo biloba constituents," European Journal of Pharmaceutical Sciences, vol. 3, no. 1, pp. 39-48, 1995.

[289] P. F. Smith, K. Maclennan, and C. L. Darlington, “The neuroprotective properties of the Ginkgo biloba leaf: a review of the possible relationship to platelet-activating factor (PAF)," Journal of Ethnopharmacology, vol. 50, no. 3, pp. 131-139, 1996. 
[290] B. Ahlemeyer and J. Krieglstein, "Neuroprotective effects of Ginkgo biloba extract," Cellular and Molecular Life Sciences, vol. 60, no. 9, pp. 1779-1792, 2003.

[291] W.-R. Wu and X.-Z. Zhu, "Involvement of monoamine oxidase inhibition in neuroprotective and neurorestorative effects of Ginkgo biloba extract against MPTP-induced nigrostriatal dopaminergic toxicity in C57 mice," Life Sciences, vol. 65, no. 2, pp. 157-164, 1999.

[292] Z. Li, K. Ya, W. Xiao-Mei, Y. Lei, L. Yang, and Z. M. Qian, "Ginkgolides protect PC12 cells against hypoxia-induced injury by $\mathrm{p} 42 / \mathrm{p} 44$ MAPK pathway-dependent upregulation of HIF-1 $\alpha$ expression and HIF-1 DNA-binding activity," Journal of Cellular Biochemistry, vol. 103, no. 2, pp. 564-575, 2008.

[293] S. Ma, H. Yin, L. Chen, H. Liu, M. Zhao, and X. Zhang, "Neuroprotective effect of ginkgolide $\mathrm{K}$ against acute ischemic stroke on middle cerebral ischemia occlusion in rats," Journal of Natural Medicines, vol. 66, no. 1, pp. 25-31, 2012.

[294] S. Ma, H. Liu, and H. Jiao, "Neuroprotective effect of ginkgolide $\mathrm{K}$ on glutamate-induced cytotoxicity in PC 12 cells via inhibition of ROS generation and $\mathrm{Ca}^{2+}$ influx," NeuroToxicology, vol. 33, no. 1, pp. 59-69, 2012.

[295] M. Huang, Y. Qian, T. Guan, L. Huang, X. Tang, and Y. $\mathrm{Li}$, "Different neuroprotective responses of Ginkgolide B and bilobalide, the two Ginkgo components, in ischemic rats with hyperglycemia," European Journal of Pharmacology, vol. 677, no. 1-3, pp. 71-76, 2012.

[296] F. V. Defeudis, "Bilobalide and neuroprotection," Pharmacological Research, vol. 46, no. 6, pp. 565-568, 2002.

[297] H. Meng, C. Li, L. Feng et al., "Effects of Ginkgolide B on 6OHDA-induced apoptosis and calcium over load in cultured PC12," International Journal of Developmental Neuroscience, vol. 25, no. 8, pp. 509-514, 2007.

[298] S. M. Nabavi, S. Habtemariam, M. Daglia et al., "Neuroprotective effects of ginkgolide B against ischemic stroke: A review of current literature," Current Topics in Medicinal Chemistry, vol. 15, no. 21, pp. 2222-2232, 2015.

[299] I. Gill, S. Kaur, N. Kaur, M. Dhiman, and A. K. Mantha, "Phytochemical Ginkgolide B Attenuates Amyloid- $\beta 1-42$ Induced Oxidative Damage and Altered Cellular Responses in Human Neuroblastoma SH-SY5Y Cells," Journal of Alzheimer's Disease, pp. 1-16, 2017.

[300] J. Xu, Y. Guo, P. Zhao et al., "Neuroprotective cadinane sesquiterpenes from the resinous exudates of Commiphora myrrha," Fitoterapia, vol. 82, no. 8, pp. 1198-1201, 2011.

[301] H. Turkez, B. Togar, and A. Tatar, "Tricyclic sesquiterpene copaene prevents H2O2-induced neurotoxicity," Journal of Intercultural Ethnopharmacology, vol. 3, no. 1, pp. 21-28, 2014.

[302] L. Pan, P. Xu, X. Luo et al., "Shizukaol B, an active sesquiterpene from Chloranthus henryi, attenuates LPS-induced inflammatory responses in BV2 microglial cells," Biomedicine \& Pharmacotherapy, vol. 88, pp. 878-884, 2017.

[303] L.-J. Wang, J. Xiong, S.-T. Liu, X.-H. Liu, and J.-F. Hu, "Sesquiterpenoids from chloranthus henryi and their antineuroinflammatory activities," Chemistry and Biodiversity, vol. 11, no. 6, pp. 919-928, 2014.

[304] D. K. More and S. Choi, "Neuroprotective Role of Atractylenolide-I in an In Vitro and In Vivo Model of Parkinson's Disease," Nutrients, vol. 9, no. 5, p. 451, 2017.

[305] Y. Xing, N. Li, D. Zhou et al., "Sesquiterpene Coumarins from Ferula sinkiangensis Act as Neuroinflammation Inhibitors," Planta Medica, vol. 83, no. 1-2, pp. 135-142, 2017.
[306] J. Y. Seo, S. S. Lim, J. Kim, K. W. Lee, and J. Kim, "Alantolactone and isoalantolactone prevent amyloid $\beta 25-35$-induced toxicity in mouse cortical neurons and scopolamine-induced cognitive impairment in mice," Phytotherapy Research, vol. 31, no. 5, pp. 801-811, 2017.

[307] D.-Z. Liu, K.-Q. Xie, X.-Q. Ji, Y. Ye, C.-L. Jiang, and X.-Z. Zhu, "Neuroprotective effect of paeoniflorin on cerebral ischemic rat by activating adenosine $A_{1}$ receptor in a manner different from its classical agonists," British Journal of Pharmacology, vol. 146, no. 4, pp. 604-611, 2005.

[308] H.-Q. Liu, W.-Y. Zhang, X.-T. Luo, Y. Ye, and X.-Z. Zhu, "Paeoniflorin attenuates neuroinflammation and dopaminergic neurodegeneration in the MPTP model of Parkinson's disease by activation of adenosine $\mathrm{A}_{1}$ receptor," British Journal of Pharmacology, vol. 148, no. 3, pp. 314-325, 2006.

[309] D.-Z. Liu, J. Zhu, D.-Z. Jin et al., "Behavioral recovery following sub-chronic paeoniflorin administration in the striatal 6OHDA lesion rodent model of Parkinson's disease," Journal of Ethnopharmacology, vol. 112, no. 2, pp. 327-332, 2007.

[310] B.-Y. Cao, Y.-P. Yang, W.-F. Luo et al., "Paeoniflorin, a potent natural compound, protects PC12 cells from $\mathrm{MPP}^{+}$and acidic damage via autophagic pathway," Journal of Ethnopharmacology, vol. 131, no. 1, pp. 122-129, 2010. 


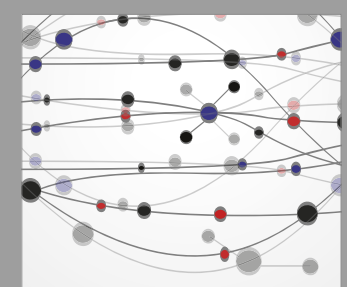

The Scientific World Journal
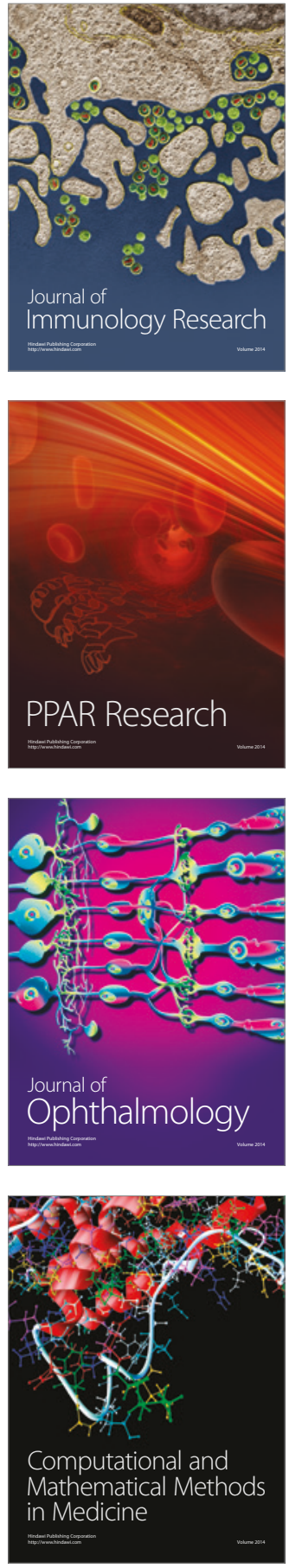

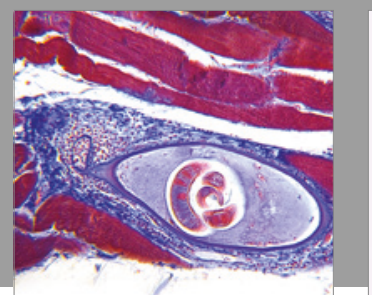

Gastroenterology Research and Practice
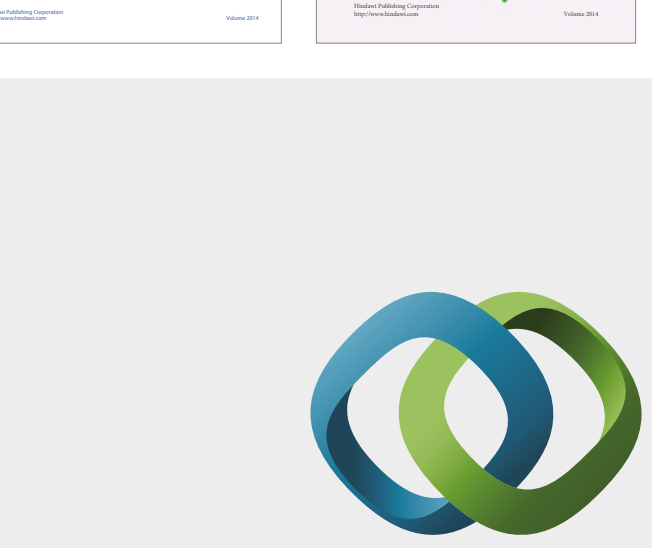

\section{Hindawi}

Submit your manuscripts at

https://www.hindawi.com
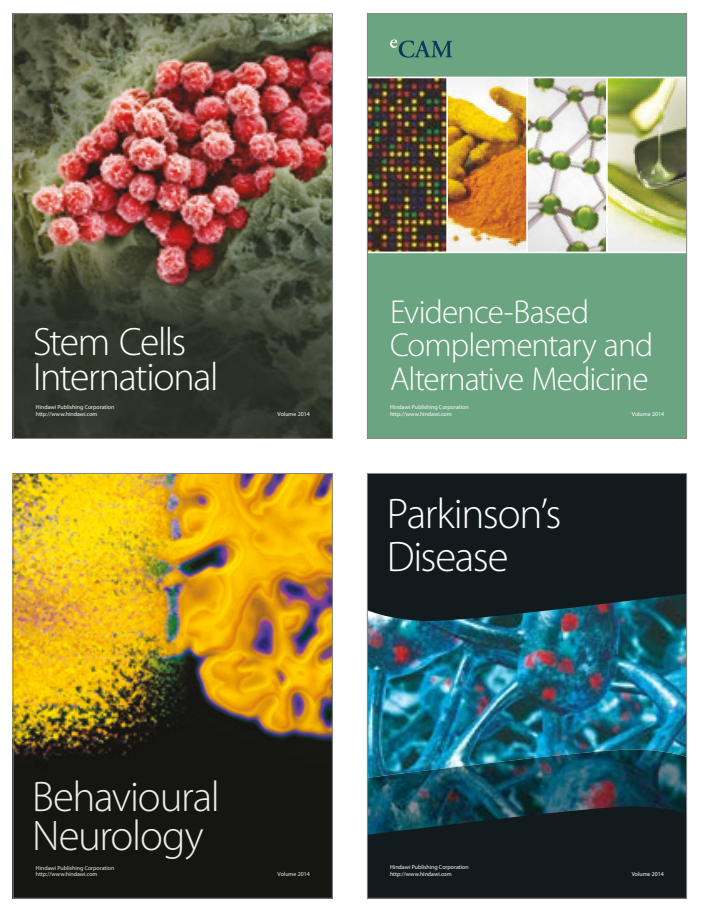
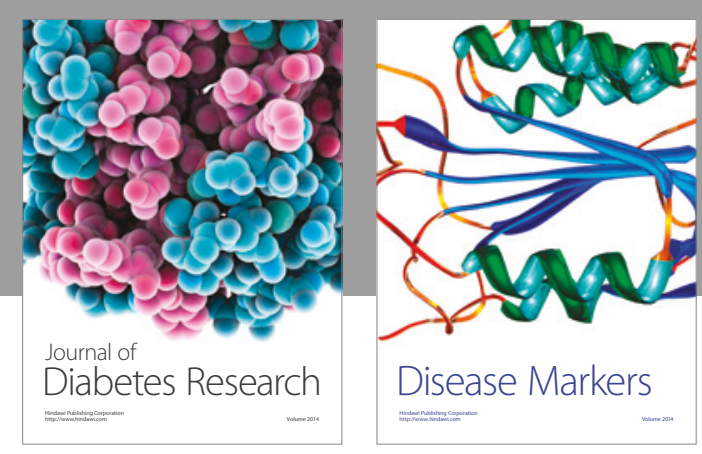

Disease Markers
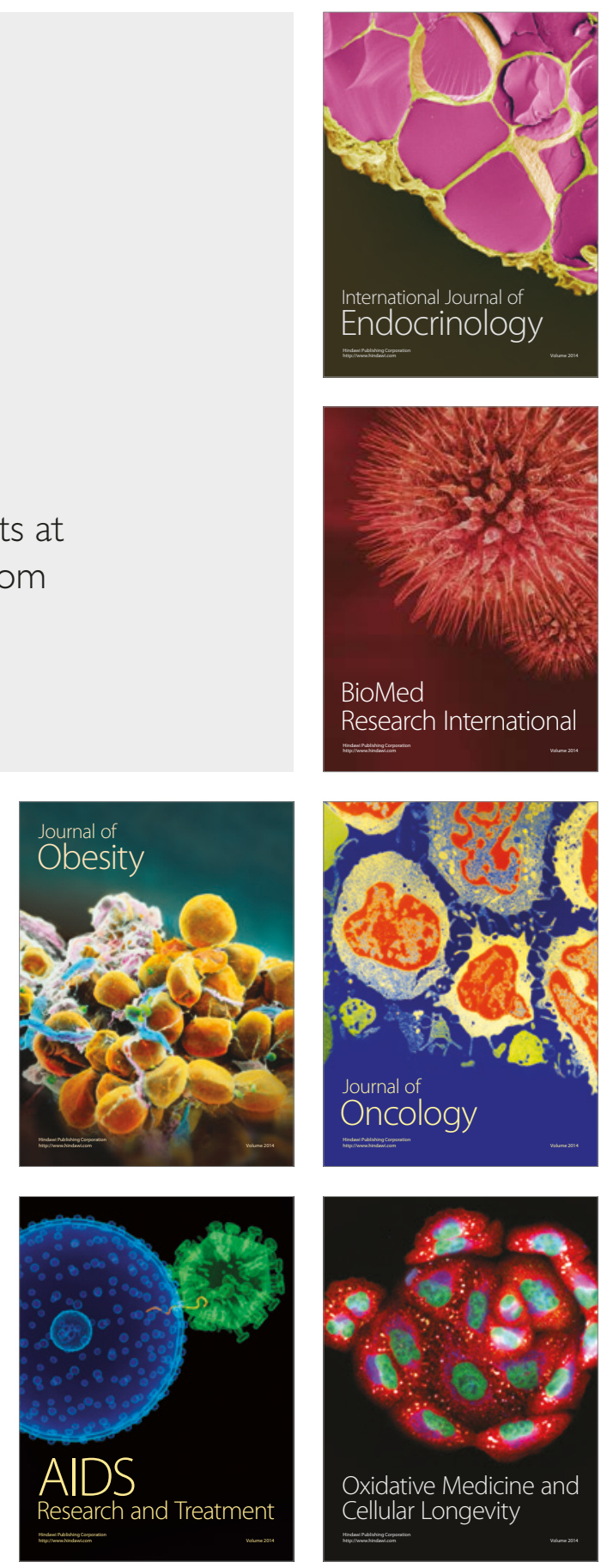